\title{
Revisiting the carbon isotope discrimination and water use efficiency relation: the influence of mesophyll conductance
}

\author{
Wei Ting Ma ${ }^{1}$, Guillaume Tcherkez ${ }^{2,3}$, Xu Ming Wang ${ }^{1}$, Rudi Schäufele ${ }^{4}$, Hans Schnyder ${ }^{4}$, \\ Yusheng Yang ${ }^{1}$, Xiao Ying Gong ${ }^{1 *}$ \\ ${ }^{1}$ Key Laboratory for Subtropical Mountain Ecology (Ministry of Science and Technology and Fujian Province \\ Funded), College of Geographical Science, Fujian Normal University, Fuzhou, 350007, China. \\ ${ }^{2}$ Research School of Biology, ANU College of Medicine, Biology and Environment, Australian National \\ University, Canberra ACT 0200, Australia. \\ ${ }^{3}$ Institut de Recherche en Horticulture et Semences, INRAe, Université d'Angers, 42 rue Georges Morel, 49070 \\ Beaucouzé, France. \\ ${ }^{4}$ Lehrstuhl für Grünlandlehre, Technische Universität München, Alte Akademie 12, 85354 Freising, Germany. \\ * Corresponding author:
}

Xiao Ying Gong, Tel. +86 59183465214, Email: xgong@ fjnu.edu.cn 


\section{Summary}

- The carbon isotope discrimination $(\Delta)$ has been used widely to infer intrinsic water-use efficiency (iWUE) of $\mathrm{C}_{3}$ plants, a key parameter linking carbon and water fluxes. Despite the essential role of mesophyll conductance $\left(g_{\mathrm{m}}\right)$ in photosynthesis and $\Delta$, its effect on $\Delta$-based predictions of iWUE has generally been neglected.

- Here, we derive a mathematical expression of iWUE as a function of $\Delta$ that includes $g_{\mathrm{m}}$ (iWUEmes) and exploits the $g_{\mathrm{m}}$-stomatal conductance $\left(g_{\mathrm{sc}}\right)$ relationship across drought-stress levels and plant functional groups (deciduous or semi-deciduous woody, evergreen woody and herbaceous species) in a global database. iWUE $_{\text {mes }}$ was further validated with an independent dataset of online- $\Delta$ and $\mathrm{CO}_{2}$ and $\mathrm{H}_{2} \mathrm{O}$ gas exchange measurements with seven species.

- Drought stress reduced $g_{\mathrm{sc}}$ by $52 \%$ and $g_{\mathrm{m}}$ by $45 \%$ averaged over all plant functional groups, but had no significant effect on the $g_{\mathrm{sc}} / g_{\mathrm{m}}$ ratio, suggesting a well-constrained $g_{\mathrm{sc}} / g_{\mathrm{m}}$ ratio of $0.79 \pm 0.07$ (95\%CI, $n=198)$ across plant functional groups and drought-stress treatments. Due in part to the synchronous behavior of $g_{\mathrm{sc}}$ and $g_{\mathrm{m}}, g_{\mathrm{m}}$ was negatively correlated to iWUE. Incorporating the $g_{\mathrm{sc}} / g_{\mathrm{m}}$ ratio in the $\mathrm{iWUE}$ mes model significantly improved the estimation of iWUE compared to the simple model.

- The inclusion of $g_{\mathrm{m}}$ effects, even using a fixed $g_{\mathrm{sc}} / g_{\mathrm{m}}$ ratio of 0.79 when $g_{\mathrm{m}}$ is unknown, proved desirable to eliminate significant bias in estimating iWUE from $\Delta$ across various $\mathrm{C}_{3}$ vegetation types.

Key words: stable isotope; water use efficiency; transpiration; drought stress; stomatal conductance; mesophyll conductance; ${ }^{13} \mathrm{C}$ discrimination; photosynthesis. 


\section{INTRODUCTION}

Water use efficiency (WUE) is a capital parameter of leaf physiology to assess photosynthetic performance and the trade-off between $\mathrm{CO}_{2}$ fixation and water loss. In addition to photosynthetic capacity, the key actor of WUE is stomatal conductance, which effectively plays a pivotal role in terrestrial carbon and water cycles because it constrains the diffusion of $\mathrm{CO}_{2}\left(g_{\mathrm{sc}}\right)$ and water vapor ( $g_{\mathrm{sw}}$, with $\left.g_{\mathrm{sw}}=1.6 g_{\mathrm{sc}}\right)$ between leaf photosynthetic tissues and the atmosphere. Leaf intrinsic water use efficiency (iWUE; see definitions in Table 1) is thus defined as the net photosynthetic rate $\left(A_{\mathrm{n}}\right)$ per unit $g_{\mathrm{sw}}$ and is given by (disregarding boundary layer resistance):

$$
\mathrm{iWUE}=\frac{A_{n}}{g_{s w}}=\frac{c_{a}}{1.6} \cdot\left(1-\frac{c_{i}}{c_{a}}\right)
$$

where $c_{\mathrm{a}}$ is the concentration of $\mathrm{CO}_{2}$ in the atmosphere and $c_{\mathrm{i}}$ the intercellular $\mathrm{CO}_{2}$ concentration. iWUE is useful to both describe plant physiological responses to environmental parameters (such as temperature and water availability) and understand the role of vegetation in hydrological cycles via its influence on water vapor and thus rainfall and runoff at regional to continental scales (Betts et al., 2007; Kooperman et al., 2018). As such, some researchers have called for more quantitative data on iWUE values in response to climate change to improve climate predictions (Adams et al., 2019, 2020). However, our ability to predict the response of carbon and water cycles in a changing climate depends ultimately on our understanding of mechanisms that control variation in iWUE.

Our current knowledge of iWUE is mostly based on its relationship with the photosynthetic ${ }^{12} \mathrm{C} /{ }^{13} \mathrm{C}$ isotope discrimination ( $\Delta$, Farquhar et al., 1982, 1989), which explicitly describes the isotopic fractionation associated with physical and biochemical processes during photosynthetic gas exchange. Using the simplified, linear relationship of Farquhar et al. (1982), neglecting mesophyll resistance (i.e. assuming an infinite internal conductance), the intrinsic water use efficiency (here denoted as iWUE $E_{\text {sim }}$, see Table 1 for definitions) is obtained from $c_{\mathrm{i}} / c_{\mathrm{a}}$ as:

$$
\mathrm{iWUE}_{\mathrm{sim}}=\frac{c_{a}}{1.6} \cdot \frac{b^{\prime}-\Delta}{b^{\prime}-a}
$$

where $a\left(4.4 \%\right.$ ) is the ${ }^{12} \mathrm{C} /{ }^{13} \mathrm{C}$ discrimination during $\mathrm{CO}_{2}$ diffusion through stomata, $b^{\prime}(27 \% 0)$ is the net discrimination during carboxylation (includes the potential contribution of effects other than Rubisco-catalysed reactions), and $\Delta$ is the net fractionation during photosynthesis that can be calculated from the isotope composition $\left(\delta^{13} \mathrm{C}\right)$ of atmospheric $\mathrm{CO}_{2}$ and plant fixed carbon (Farquhar \& Richards, 1984; Ubierna et al., 2018). $\Delta$ can be estimated from on-line ${ }^{13} \mathrm{CO}_{2} /{ }^{12} \mathrm{CO}_{2}$ 
gas exchange during photosynthesis or the $\delta^{13} \mathrm{C}$ of photosynthetic products (e.g. sugars and bulk

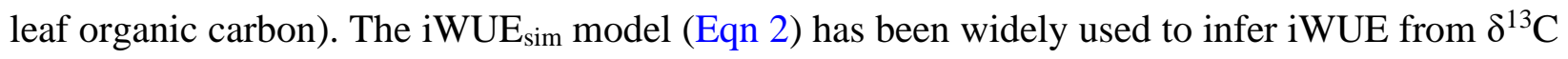
values in climate archives like herbage (Koehler et al., 2012), tree rings (Frank et al., 2013; van der Sleen et al., 2015), or animal tissues (Barbosa et al., 2010). Compared to instantaneous iWUE derived from gas exchange measurements, biomass-based $\Delta$ provides a time-integrated iWUE and enables time-series analysis spanning from days to millennia (Soh et al., 2019; Adams et al., 2020). This time-integrated iWUE is particularly useful for screening of high water-use efficiency crops thus has been used in breeding programs (for a review, see Flexas et al., 2013). Similarly, genetic determinants of iWUE have been searched for nearly 25 years using biomass-based $\Delta$ as a quantitative trait in QTL analyses (Rebetzke et al. 2008; Yang et al. 2016). Also, using surveys with many plant samples of diverse origins, spatial variation in vegetation iWUE could be assessed or integrated at a regional (Wittmer et al., 2010) or global scale (Cornwell et al., 2018; Adams et $a l ., 2020)$. More recently, $\delta^{13} \mathrm{C}$-derived iWUE, together with transpiration inferred from sap flow, have been used to estimate canopy photosynthesis (Klein et al., 2016). However, it has been argued that the $\mathrm{iWUE}_{\text {sim }}$ model gives biased predictions of iWUE, limiting its application to qualitative assessments (Seibt et al., 2008; Barbosa et al., 2010).

In fact, the main limitation of the use of $\mathrm{iWUE}_{\text {sim }}$ is the simplifying assumption that mesophyll conductance $\left(g_{\mathrm{m}}\right.$, the diffusive conductance of $\mathrm{CO}_{2}$ from intercellular space to the site of carboxylation) is infinite (Seibt et al., 2008; Franks et al., 2013; Stangl et al., 2019). This assumption, theoretically, leads to an overestimation of iWUE (see Theory below) because $g_{\mathrm{m}}$ is not conservatively high (for reviews see Flexas et al., 2008, 2012) and thus this causes an increased $\mathrm{CO}_{2}$ drawdown from the atmosphere to chloroplasts and thereby decreases the actual isotope fractionation $\Delta$. Furthermore, responses of $g_{\mathrm{m}}$ to environmental stimuli have been reported, including water stress (Galmes et al., 2007; Warren et al., 2011; Barbour \& Kaiser, 2016), temperature (Yamori et al., 2006; Evans \& Von Caemmerer, 2013), and $\mathrm{CO}_{2}$ mole fraction (Flexas et al., 2007; Tazoe et al., 2011). In other words, applying either an infinite or a species-specific, constant $g_{\mathrm{m}}$ in iWUE models is perhaps improper. Water stress is particularly relevant in the context of water utilization by plant leaves, because it strongly influences $g_{\text {sw }}$ and thus iWUE (Lin et al., 2015). However, its impact on $g_{\mathrm{m}}$ is currently uncertain. Some studies have reported that both $g_{\mathrm{m}}$ and $g_{\mathrm{sw}}$ decreased under edaphic drought, i.e. low soil water content (Galmes et al., 2007; Cano et al., 2014). In addition, while stomatal limitation of photosynthetic gas exchange has been 
found to be the dominant factor in the early stage of drought, the decrease in $g_{\mathrm{m}}$ further restricts photosynthesis later on (Perez-Martin et al., 2014). Vapor pressure deficit (VPD), a key factor that influences both plant water potential and stomatal conductance, has been found to decrease (Loucos et al., 2017) or have no influence on $g_{\mathrm{m}}$ (Warren, 2008; Stangl et al., 2019). In principle, a low sensitivity of $g_{\mathrm{m}}$ to water deficit is beneficial for maintaining a high $\mathrm{CO}_{2}$ assimilation rate (Cano et al., 2014). That is, a combination of a low $\mathrm{g}_{\mathrm{sw}}$ and a high $g_{\mathrm{m}}$ should lead to a high iWUE if photosynthetic capacity is maintained (Barbour et al., 2010; Flexas et al., 2013; Barbour \& Kaiser, 2016). Accordingly, $g_{\mathrm{m}}$ has been suggested to be an important target for crop improvement (Cano et al., 2014; Barbour \& Kaiser, 2016), although this hypothesis was not supported by experimental results of wheat genotypes (Barbour \& Kaiser, 2016). Therefore, the responses of $g_{\mathrm{m}}$ and $g_{\text {sw }}$ to long-term drought stress is not well understood, and the implication for iWUE estimation is not clear.

Having said that, incorporating mesophyll conductance is still challenging because measuring $g_{\mathrm{m}}$ involves technically demanding methods, such as online carbon isotope discrimination (Evans et al., 1986), chlorophyll fluorescence (Harley et al., 1992), or ${ }^{18} \mathrm{O}$ mass balance (Gauthier et al. 2018). This explains why $g_{\mathrm{m}}$ measurements cannot be carried out at high-throughput and therefore, our knowledge of mechanisms driving variation in $g_{\mathrm{m}}$ is still limited. In practice, there is presently no available method to incorporate $g_{m}$ effects in iWUE and carbon cycle models derived therefrom (Flexas et al., 2012; Sun et al., 2014a). Alternatively, empirical estimates can be used to scale $g_{\mathrm{m}}$ to other photosynthetic parameters, since $g_{\mathrm{m}}$ has been shown to be positively related to net assimilation rate or $g_{\mathrm{sc}}$ (Flexas et al., 2008; Gong et al., 2018). Such relationships could be useful - providing they are well-constrained - for improving estimates of iWUE. However, such relationships have not been tested with a global compiled dataset of a diverse range of functionally distinct species.

Taken as a whole, the broad application of ${ }^{12} \mathrm{C} /{ }^{13} \mathrm{C}$ isotope fractionation to compute intrinsic water use efficiency generally neglects the impact of mesophyll conductance, either because of technical reasons (difficult access to mesophyll conductance measurements) or because its impact is assumed to be relatively modest (assumption of infinite $g_{\mathrm{m}}$ in iWUEsim). However, the reliability of iWUE estimates omitting mesophyll conductance is questionable, in particular when the photosynthetic limitation associated with mesophyll resistance is large. Here, we derive an expression of iWUE that includes the effect of $g_{\mathrm{m}}$ (denoted as $\mathrm{iWUE}_{\mathrm{mes}}$ ), and test the numerical 
impact of $g_{\mathrm{m}}$ using independent experimental datasets. We address the following questions: 1) can we substantially improve the prediction of iWUE (compared with iWUEsim) by including a term accounting for $g_{\mathrm{m}}$ ? and, 2) could we take advantage of a $g_{\mathrm{m}} g_{\mathrm{sc}}$ relationship and if so, can it be generalized to compute iWUE? To answer these questions, we collated a database of more than 300 pairs of $g_{\mathrm{sc}}$ and $g_{\mathrm{m}}$ measurements of more than 84 species from $>40$ publications. We analyzed the response of $g_{\mathrm{m}}$ and $g_{\mathrm{sc}}$ to long-term drought stress in different plant functional groups to parameterize iWUEmes. To test whether $\mathrm{iWUE}_{\text {mes }}$ provides reliable estimates of intrinsic water use efficiency, we used an independent dataset of iWUE $_{\text {obs }}$ values (obtained directly from gas exchange), and on-line photosynthetic $\Delta$ corrected for side effects of respiratory isotopic imbalance (Gong et al., 2015). The latter dataset compiled measurements obtained with seven species grown in controlled-environment conditions.

\section{MATERIALS AND METHODS}

\section{Theory}

Farquhar et al. (1982) and Farquhar \& Cernusak (2012) established a comprehensive theoretical model to describe the photosynthetic ${ }^{13} \mathrm{C}$ discrimination of $\mathrm{C}_{3}$ leaves $(\Delta)$ as:

$$
\Delta=\frac{1}{1-t}\left[a_{a c} \frac{c_{a}-c_{i}}{c_{a}}\right]+\frac{1+t}{1-t}\left[a_{m} \frac{c_{i}-c_{c}}{c_{a}}+b \frac{c_{c}}{c_{a}}+\frac{\alpha_{b}}{\alpha_{e}} e \frac{R_{d}\left(c_{c}-\Gamma^{*}\right)}{\left(A_{n}+R_{d}\right) c_{a}}-\frac{\alpha_{b}}{\alpha_{f}} f \frac{\Gamma^{*}}{c_{a}}\right]
$$

where $c_{\mathrm{a}}, c_{\mathrm{s}}, c_{\mathrm{i}}$ and $c_{\mathrm{c}}$ are $\mathrm{CO}_{2}$ mole fractions in the atmosphere, at the leaf surface, and in the substomatal cavity and chloroplast, respectively. $a_{\mathrm{m}}(1.8 \% \mathrm{o})$ is the fractionation associated with $\mathrm{CO}_{2}$ dissolution and diffusion in the mesophyll; $R_{\mathrm{d}}$ represents the day respiration rate; $\Gamma^{*}$ is the $\mathrm{CO}_{2}$ compensation point in the absence of mitochondrial respiration.; $b$ (29\%o), $e$ (-6-0\%o) and $f$ (11\%o) represent the fractionations due to carboxylation, daytime mitochondrial respiration and photorespiration, respectively. Also, $\alpha_{b}=1+b, \alpha_{e}=1+e, \alpha_{f}=1+f . t$ is the ternary correction factor and $a_{\mathrm{ac}}$ is the weighted fractionation for diffusion across the boundary layer and stomata. They can be calculated as:

$$
\begin{gathered}
t=\frac{\left(1+a_{a c}\right) E}{2 g_{a c}} \\
a_{a c}=\frac{a_{b}\left(c_{a}-c_{s}\right)+a_{s}\left(c_{s}-c_{i}\right)}{c_{a}-c_{i}}
\end{gathered}
$$

where $a_{\mathrm{b}}\left(2.9 \%\right.$ ) and $a_{\mathrm{s}}\left(4.4 \%\right.$ ) are the ${ }^{12} \mathrm{C} /{ }^{13} \mathrm{C}$ fractionations during $\mathrm{CO}_{2}$ diffusion through the leaf boundary layer and stomata, respectively. $E$ is the transpiration rate. $c_{\mathrm{s}}$ is the $\mathrm{CO}_{2}$ concentration at the leaf surface; $g_{\text {ac }}$ is the combined boundary layer and stomatal conductance to $\mathrm{CO}_{2}$. 
From this point, we can use $\Delta$ to calculate an exact value of intrinsic water use efficiency that accounts for both internal conductance and ternary effects. It will be denoted as iWUE $E_{\text {com. }}$ We recall here that accounting for ternary effects is so that:

$$
A_{n}=g_{a c}\left(c_{a}-c_{i}\right)-E \bar{c} \text { where } \bar{c}=\frac{c_{a}+c_{i}}{2}
$$

At this stage, there are two possibilities to compute intrinsic water use efficiency: accounting for boundary layer conductance, or disregarding boundary layer resistance. As per Eqn 3 to 5, the observed isotope fractionation accounts for boundary layer effects and the $\mathrm{CO}_{2}$ drawdown from $c_{a}$ to $c_{i}$ is the result of both boundary layer and stomatal resistance.

- If the definition of intrisic water use efficiency encapsulates both boundary layer and stomatal effects (we denote this iWUE as iWUE ${ }_{\text {com }}^{*}$ ), we have:

$$
\mathrm{iWUE}_{\mathrm{com}}^{*}=\frac{A_{n}}{k g_{a c}}=\frac{g_{a c}\left(c_{a}-c_{i}\right)-E \bar{c}}{k g_{a c}}
$$

Where $k$ is the coefficient between $\mathrm{CO}_{2}$ and $\mathrm{H}_{2} \mathrm{O}$ conductances (it equals 1.6 in Eqn 1). Using the expression $E=k g_{a c} W$ (where $W$ is the water vapor drawdown from intercellular spaces to air), we have:

$$
\mathrm{iWUE}_{\mathrm{com}}^{*}=c_{a} \cdot\left(\frac{1}{k}-\frac{W}{2}\right)-c_{i} \cdot\left(\frac{1}{k}+\frac{W}{2}\right)
$$

Substituting Eqns 6 and 7 into 3, we have (for intermediate calculations, see Note S1):

$$
\mathrm{iWUE}_{\mathrm{com}}^{*}=c_{a} \frac{a_{a c}(1-\varepsilon)+(1+t)\left[\frac{\Gamma^{*}}{c_{a}}\left(\frac{e^{\prime} R_{d}}{A_{n}+R_{d}}-f^{\prime}\right)+\varepsilon\left(b-\frac{e^{\prime} R_{d}}{A_{n}+R_{d}}\right)\right]-(1-t) \Delta}{\frac{(1+t)\left(b-\frac{e^{\prime} R_{d}}{A_{n}+R_{d}}\right)-a_{a c}}{\frac{1}{k}+\frac{W}{2}}-(1+t) k \frac{g_{a c}}{g_{m}}\left(a_{m}-b+\frac{e^{\prime} R_{d}}{A_{n}+R_{d}}\right)}
$$

where $e^{\prime}=e \alpha_{b} / \alpha_{e}, f^{\prime}=f \alpha_{b} / \alpha_{f}$ and

$$
\varepsilon=\frac{\frac{1}{k}-\frac{W}{2}}{\frac{1}{k}+\frac{W}{2}}
$$

Here, it is useful to indicate the order of magnitude of terms found in Eqn 8 but not found in simplified expressions commonly used (such as Eqn 2). Assuming that $E$ is typically about 2 mmol $\mathrm{m}^{-2} \mathrm{~s}^{-1}$ and stomatal conductance for $\mathrm{CO}_{2}$ is $0.1 \mathrm{~mol} \mathrm{~m}^{-2} \mathrm{~s}^{-1}$ gives $t$ in the order of $1 / 100^{\text {th }}$ thus its impact is small. $W$ is homogenous to a mole fraction and thus about 0.01 (i.e. typically in the order of $10 \mathrm{mmol} \mathrm{H}_{2} \mathrm{O} \mathrm{mol}^{-1}$ ) and thus $\varepsilon \approx 0.98$ and its impact is rather small. Taken as a whole, the ternary correction affects iWUE by about $1 \%$. 
- If intrinsic water use efficiency does not encapsulate boundary layer effects (it is then denoted as

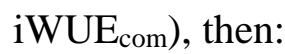

$$
\mathrm{iWUE}_{\mathrm{com}}=\frac{A_{n}}{k g_{s c}}=\frac{A_{n}}{k g_{a c}} \cdot \frac{g_{a c}}{g_{s c}}=\mathrm{iWUE}_{\mathrm{com}}^{*} \frac{g_{a c}}{g_{s c}}
$$

Note that Eqn 10 means that boundary layer effects are so that $\mathrm{iWUE}_{\mathrm{com}}<\mathrm{iWUE}_{\text {com }}$ since $g_{a c}<$ $g_{s c}$. When ternary corrections are ignored and boundary layer conductance is presumed to be infinite, then $t=0, \varepsilon=1, c_{\mathrm{a}}=c_{\mathrm{s}}$ and thus $a_{\mathrm{ac}}=a_{\mathrm{s}}$ and $g_{\mathrm{ac}=} g_{\mathrm{sc}}$. Eqn 8 simplifies to:

$$
\mathrm{iWUE}_{\mathrm{mes}}=\frac{c_{a}}{k} \frac{b-\Delta-f^{\prime} \frac{\Gamma^{*}}{c_{a}}-e^{\prime} \frac{R_{d}}{A_{n}+R_{d}}\left(1-\frac{\Gamma^{*}}{c_{a}}\right)}{b-a_{s}+\frac{g_{s c}}{g_{m}}\left(b-a_{m}+e^{\prime} \frac{R_{d}}{A_{n}+R_{d}}\right)-e^{\prime} \frac{R_{d}}{A_{n}+R_{d}}}
$$

Here, the subscript "mes" indicates that this expression accounts for mesophyll conductance effects but not ternary correction or boundary layer effects. If the impact of day respiration is assumed to be negligible ( $e=0$ ), or if the photosynthetic fractionation has been corrected for $R_{\mathrm{d}}$ (see below), Eqn 11 gives the proxy:

$$
\mathrm{iWUE}_{\mathrm{mes}}=\frac{c_{a}}{k} \frac{b-\Delta-f^{\prime} \frac{\Gamma^{*}}{c_{a}}}{b-a_{s}+\frac{g_{s c}}{g_{m}}\left(b-a_{m}\right)}
$$

The simplifying assumptions used here to obtain Eqn 12, which have been commonly applied (Ubierna et al., 2018), are supported by sensitivity tests (see below). Compared with iWUE sim $_{\text {(Eqn }}$ 2), iWUE $_{\text {mes }}$ (Eqn 12) takes into account the effects of mesophyll conductance and photorespiration. Combining Eqn 12 and Eqn 2, iWUEmes is related to iWUE $\mathrm{i}_{\text {sim }}$ as:

$$
\mathrm{iWUE}_{\text {mes }}=\frac{c_{a}\left(b-b^{\prime}\right)+k \mathrm{iWUE}_{\operatorname{sim}}\left(b^{\prime}-a_{s}\right)-f^{\prime} \Gamma^{*}}{k\left(b-a_{s}+\left(b-a_{m}\right) \frac{g_{s c}}{g_{m}}\right)}
$$

Eqn 12 can also be used to examine the sensitivity of $\mathrm{iWUE}_{\mathrm{mes}}$ with respect to the $g_{\mathrm{sc}}$-to- $g_{\mathrm{m}}$ ratio. Using the partial derivative of $\mathrm{iWUE}_{\mathrm{mes}}$ gives the elasticity (relative change in $\mathrm{iWUE}_{\mathrm{mes}}$ for a unit variation in $\left.g_{\mathrm{sc}} / g_{\mathrm{m}}\right)$ :

$$
\frac{\partial \ln \left(\mathrm{iWUE}_{\mathrm{mes}}\right)}{\partial \ln \left(\frac{g_{S c}}{g_{m}}\right)}=\frac{1}{1+\frac{b-a_{s}}{b-a_{m}} \cdot \frac{g_{m}}{g_{s c}}}
$$

To assess the sensitivity of iWUE models (Eqn 8, 10 and 12) to different simplifications, we used theoretical data and varied the photosynthetic discrimination within 18 and 22\%o at different $g_{\mathrm{sc}} / g_{\mathrm{m}}$ ratios: $g_{\mathrm{sc}} / g_{\mathrm{m}}=0$ (iWUE $\left.\mathrm{ism}_{\text {model }}\right), g_{\mathrm{sc}} / g_{\mathrm{m}}=0.4,0.8$ and 1.6 (iWUE (for details on calculations, see Table S1). 


\section{Collection of literature data of $g_{m}$ and $g_{s c}$}

To parameterize $g_{\mathrm{sc}} / g_{\mathrm{m}}$ in Eqn 12, we performed an extensive literature review of leaf-level $g_{\mathrm{m}}$ and $g_{\text {sc }}$ measurements by searching the keywords 'mesophyll conductance' and 'internal conductance' in ISI Web of Science and checking the cited references in recent review articles of this topic. Data published before 2020 that met the following criteria were included in our analyses: (i) leaf-level $g_{\mathrm{m}}$ and $g_{\mathrm{sc}}$ data were reported; (ii) $g_{\mathrm{m}}$ was measured with either the online carbon isotope discrimination (Evans et al. 1986) or fluorescence (Harley et al., 1992) methods; and (iii) both control and edaphic drought treatments were included. We neglected results with short-term drought treatment (i.e. exposure time shorter than 2 days) and results of re-watering experiments, since acclimated parameters are more representative for the steady-state physiological status of plants compared with dynamically changing parameters. Gas exchange parameters (e.g. net assimilation rate, transpiration rate) were also collected if presented. Furthermore, we eliminated outliers which were defined by the criteria: $A_{\mathrm{n}} / g_{\mathrm{sc}}>300, g_{\mathrm{sc}} / g_{\mathrm{m}}<0.2$, or $g_{\mathrm{m}}>0.8 \mathrm{~mol} \mathrm{~m}^{-2} \mathrm{~s}^{-1}$ (cf. Flexas et al., 2013). Average values for of each species in each treatment combination were compiled, and the compiled dataset included 198 pairs of $g_{\mathrm{m}}$ and $g_{\mathrm{sc}}$ measurements of 32 species under manipulated soil water availability or VPD from 15 studies ('drought-stress dataset'). Additionally, published data reporting long-term treatments other than edaphic drought (e.g. temperature, salinity, soil nutrients, light, etc.) were collected and screened with the same criteria to detect outliers. We thus obtained a more comprehensive dataset ('the main dataset') that included 364 pairs of $g_{\mathrm{m}}$ and $g_{\mathrm{sc}}$ measurements of 84 species from 50 studies. We used the 'drought-stress dataset' to analyze the effects of water stress treatments and plant functional groups, and 'the main dataset' was used to examine the $g_{\mathrm{sc}^{-}} g_{\mathrm{m}}$ relation in a larger dataset.

Statistical analyses on the compiled drought-stress dataset of $g_{\mathrm{m}}, g_{\mathrm{sc}}, A_{\mathrm{n}}$, and $g_{\mathrm{sc}} / g_{\mathrm{m}}$ were performed by using the general linear model of SPSS Statistics 19 (IBM Corp). The general linear model included water stress and plant functional groups (PFGs) and their interaction as the main factors. The factor of drought stress had two levels: control (non-stressed plants) and stressed. Plant species were classified into three PFGs: deciduous or semi-deciduous woody (DW), evergreen woody (EW), and herbaceous (HB, including annual, bi-annual and perennial) species. The parameters were logarithmic and square-root transformed to improve the normality before ANOVA tests or linear regressions, and both methods had no effect on the statistical results. We 
present here square-root transformed results because it improved the normality to a greater extent compared to the logarithmic transformation, as detected from histograms.

\section{Experimental data and photosynthetic ${ }^{13} \mathrm{C}$ discrimination}

To validate the iWUEmes model (Eqn 12), we used independent datasets from two experiments (Gong et al. 2015, 2018) which included simultaneous measurements of photosynthetic gas exchange and online ${ }^{13}$ Cdiscrimination on fully expanded young leaves of seven species (Table 2). Most of the data have been published with the exception of Vicia faba and Glycine max grown and measured in the same way as the other species (Gong et al., 2018). These datasets were particularly suitable for evaluating the relation between $\Delta$ and iWUE because advanced protocols were applied to minimize any effect of diffusive leaks in the leaf cuvette and the isotopic disequilibrium between photosynthesis and day respiration. That system used a ${ }^{13} \mathrm{CO}_{2} /{ }^{12} \mathrm{CO}_{2}$ gas exchange and labelling system connected with a portable leaf gas exchange apparatus (LI-6400, LICOR Inc., Lincoln, USA) and gas exchange mesocosms, with the air supply to the LI-6400 and mesocosms provided by mixing $\mathrm{CO}_{2}$-free, dry air and $\mathrm{CO}_{2}$ of known $\delta^{13} \mathrm{C}$ (Schnyder et al., 2003). This setup enabled the quantification of diffusive leak coefficients during measurements with intact leaves by measuring and manipulating ${ }^{13} \mathrm{CO}_{2}$ and ${ }^{12} \mathrm{CO}_{2}$ gradients between leaf cuvette and the surrounding air in the dark, thus effectively correcting leak artefacts (Gong et al. 2015, 2018).

The $\mathrm{iWUE}_{\text {mes }}$ model (Eqn 12) excludes the fractionation component associated with $R_{\mathrm{d}}$, therefore, to precisely compare the modeled and the observed iWUE, the isotopic fractionation of $R_{\mathrm{d}}\left(\Delta_{\mathrm{Rd}}\right)$ should be subtracted from the observed net discrimination $\left(\Delta_{\mathrm{AN}}\right)$ as $\Delta_{\mathrm{P}}=\Delta_{\mathrm{AN}}+\Delta_{\mathrm{Rd}}$, where $\Delta_{\mathrm{P}}$ is the photosynthetic discrimination corrected for day respiration. Alternatively, our experimental data can be used to parameterize Eqn 11, and in that case $\Delta_{\mathrm{Rd}}$ is not subtracted. Subtracting the effect of $R_{\mathrm{d}}$ is particularly useful when there is an isotopic disequilibrium whereby respiratory substrates have an isotope composition that is substantially different from that of current assimilates.

If we neglect ternary corrections in Eqn 3 , the $R_{\mathrm{d}}$ corrected photosynthetic discrimination $\left(\Delta_{\mathrm{P}}\right)$ can be calculated as:

$$
\Delta_{\mathrm{P}}=\Delta_{\mathrm{AN}}+e R_{\mathrm{d}}\left(c_{\mathrm{c}}-\Gamma^{*}\right) /\left[\left(A_{\mathrm{n}}+R_{\mathrm{d}}\right) c_{\mathrm{a}}\right]
$$

This equation is difficult to apply in practice because (i) the term $R_{\mathrm{d}}$ in Eqn 3 is the gross respiration rate (before refixation by photosynthesis and anapleurotic reactions) and is not easily 
measurable (Tcherkez et al. 2017); (ii) it requires the knowledge of $c_{\mathrm{c}}$ thus we would need to measure $g_{\mathrm{m}}$ first. We thus took advantage of the isotopic disequilibrium approach of Gong et al. $(2015 ; 2018)$ to subtract the term associated with $R_{\mathrm{d}}$ from $\Delta_{\mathrm{AN}}$. Assumptions on the isotope effect of $R_{\mathrm{d}}$ are further detailed in Note $\mathrm{S} 2$. Online discrimination measurements (Evans et al., 1986) were performed using a ${ }^{13} \mathrm{C}$-enriched $\mathrm{CO}_{2}$ source, followed by the measurement using a ${ }^{13} \mathrm{C}$ depleted $\mathrm{CO}_{2}$ source, so that the measured net assimilation rate $\left(A_{\mathrm{n}}\right)$ could be partitioned into net photosynthesis in the absence of day respiration $(P)$ and day respiration $\left(R_{\mathrm{d}}^{\prime}\right)$ (Gong et al., 2015). Applying isotopic mass balance, the photosynthetic discrimination $\left(\Delta_{\mathrm{P}}\right)$ was calculated from the measured net discrimination $\left(\Delta_{\mathrm{AN}}\right)$ as (Tcherkez et al., 2011; Gong et al., 2018):

$$
\Delta \mathrm{P}=\Delta_{\mathrm{AN}}+e R^{\prime}{ }_{\mathrm{d}} / A_{\mathrm{n}}
$$

where $R^{\prime}{ }_{\mathrm{d}}$ is day respiration measured by the method of Gong et al. $(2015 ; 2018)$ and $e$ is the measured isotope fractionation of $R_{\mathrm{d}}$ relative to $A_{\mathrm{n}}$ determined as $e=\left(\delta_{\mathrm{An}}-\delta_{\mathrm{Rd}}\right) /\left(1+\delta_{\mathrm{Rd}}\right)$. It is assumed that $\delta_{\mathrm{Rd}}$ was equal to the measured isotopic signature of leaf respiration in the dark (Gong et al. 2015, 2018). Importantly, Eqn 16 assumes that $\mathrm{CO}_{2}$ evolved by day respiration has a $\delta^{13} \mathrm{C}$ value that is distinct to that of photosynthesis. In other words, the calculation treats $R_{\mathrm{d}}^{\prime}$ as a flux metabolically disconnected from recent photosynthesis during a short-duration of measurements (Note S2), and the related assumptions have been validated and discussed previously (Gong et al. 2015, 2017, 2018) and supported by other work (Barbour et al., 2017; Busch et al., 2020). Furthermore, taking different assumptions concerning the value of respiratory fractionation (Eqn 3 vs. Eqn S1) eventually had very minor influence on iWUE estimates (Note S2, Fig. S4).

Knowing $\Delta_{\mathrm{P}}$, iWUE was calculated from the iWUEmes model (Eqn 12) using a mean $g_{\mathrm{sc}} / g_{\mathrm{m}}$ of 0.79 derived from the compiled literature dataset (see below), and $\Gamma^{*}$ as estimated from leaf temperature $(T)$ as $\Gamma^{*}=42.7+1.68(T-25)+0.012(T-25)^{2}$ following Brooks \& Farquhar (1985). In addition, iWUE was also calculated from the simple model (iWUE sim $_{\text {Eqn }}$ 2). The estimates of $\mathrm{iWUE}_{\mathrm{mes}}$ and $\mathrm{iWUE}_{\text {sim }}$ were compared with the measured iWUE from gas exchange measurements (iWUE ${ }_{\text {obs }}$ ). The Root Mean Square Error (RMSE) was calculated to evaluate the prediction errors for the simple and the iWUE mes model. The value of $g_{\mathrm{m}}$ of these plants was determined using the improved online $\Delta$ method and were published previously (Gong et al. 2015; 2018), except for the Vicia faba and Glycine max data. The detailed description of methods and equations for $g_{\mathrm{m}}$ are presented in Gong et al. (2015; 2018). 


\section{RESULTS}

Sensitivity of $i$ WUE models to $g_{m}$ and simplifying assumptions

The expression of $\mathrm{iWUE}_{\mathrm{mes}}$ (Eqn 12) includes the $g_{\mathrm{sc}} / g_{\mathrm{m}}$ ratio, implying in principle that iWUE $\mathrm{mes}_{\mathrm{m}}$ varies with $g_{\mathrm{m}}$. Accordingly, the expression of elasticity (Eqn 14) shows that estimating $\mathrm{iWUE}_{\mathrm{mes}}$ from $\Delta$ using Eqn 12 is sensitive to the $g_{\mathrm{sc}} / g_{\mathrm{m}}$ ratio when $g_{\mathrm{m}}$ is varied in relation to $g_{\mathrm{sc}}$. For example, as is shown below, with a very high value of $g_{\mathrm{sc}} / g_{\mathrm{m}}$, e.g. $g_{\mathrm{sc}} / g_{\mathrm{m}}=3$, the elasticity value is 0.77 . This implies a $77 \%$ change in $\mathrm{iWUE}_{\mathrm{mes}}$ when $g_{\mathrm{sc}} / g_{\mathrm{m}}$ changes by $100 \%$. By contrast, when $g_{\mathrm{m}}$ is large, the denominator in Eqn 14 is large and the elasticity value becomes small. Eqn 14 thus reflects the intuitive result that when $g_{\mathrm{m}}$ is large, its impact on $\Delta$ is small and thus numerically, the impact of the $g_{\mathrm{sc}} / g_{\mathrm{m}}$ ratio on iWUE is modest (and effectively nil, when $g_{\mathrm{m}}$ is infinite, as assumed by $\mathrm{iWUE}_{\text {sim }}$ ).

A sensitivity analysis was performed to quantify the effect of $g_{\mathrm{sc}} / g_{\mathrm{m}}$ ratio, dark respiratory fractionation $e$, photosynthetic fractionation $f$ and ternary corrections on iWUE, as predicted by the different iWUE models (Fig. 1). Both iWUE $\mathrm{Com}_{\mathrm{co}}$ and $\mathrm{iWUE}_{\mathrm{mes}}$ were sensitive to the $g_{\mathrm{sc}} / g_{\mathrm{m}}$ ratio. The simplified model (that assumed $g_{\mathrm{sc}} / g_{\mathrm{m}}=0$ ) predicted the largest iWUE, as expected (Fig. 1a). At all $g_{\mathrm{sc}} / g_{\mathrm{m}}$ ratios, iWUE $\mathrm{com}_{\mathrm{m}}$ and $\mathrm{iWUE}$ mes predictions were numerically very similar (with an error of generally less than $3 \mu \mathrm{mol} \mathrm{mol}{ }^{-1}$, Fig. 1a). Furthermore, assuming an $f$ of 0 or $20 \%$ led to a variation of predicted iWUE of about $5 \mu \mathrm{mol} \mathrm{mol}{ }^{-1}$ (Fig. 1b). Similarly, ignoring respiratory fractionation or ternary correction caused an error of less than $2 \mu \mathrm{mol} \mathrm{mol}^{-1}$ (Fig. 1cd). Also, manipulating boundary layer conductance between $1 \mathrm{~mol} \mathrm{~m}^{-2} \mathrm{~s}^{-1}$ and infinite had very little influence on iWUE estimates (error less than $2 \mu \mathrm{mol} \mathrm{mol}^{-1}$, data not shown). Thus, the assumptions we used to derive iWUEmes (Eqn 12) seem to be appropriate.

\section{Overview of $g_{m}$ and $g_{s c}$ variations}

Water availability and PFGs significantly impacted $A_{\mathrm{n}}, g_{\mathrm{sc}}$, and $g_{\mathrm{m}}$ (Table 3). Compared with the non-stressed condition, drought stress decreased $A_{\mathrm{n}}, g_{\mathrm{sc}}$, and $g_{\mathrm{m}}$ for all three PFGs significantly (Fig. 2), but the magnitude of the decrease varied between PFGs. Within a PFG, drought stress reduced $A_{\mathrm{n}}$ by $36 \%$ for the DW, $67 \%$ for the EW and $42 \%$ for the HB (Fig. 2a); and reduced $g_{\mathrm{sc}}$ by $37 \%$ for the DW, $81 \%$ for the EW and $47 \%$ for the HB (Fig. 2b), on average. The magnitude of the reduction in $g_{\mathrm{m}}$ was similar to that of $g_{\mathrm{sc}}: 36 \%$ in the DW, $80 \%$ in the $\mathrm{EW}$ and $35 \%$ in the HB PFG (Fig. 2c). The HB had the highest values of $A_{\mathrm{n}}, g_{\mathrm{sc}}$, and $g_{\mathrm{m}}$ among the three PFGs under 
both non-stressed and drought-stressed conditions (Fig. 2). That is, the higher $A_{\mathrm{n}}$, the higher were $g_{\mathrm{sc}}$ and $g_{\mathrm{m}}$ within a functional group. This relationship was generally true also for the individual species within a PFG. Accordingly, positive correlations between $A_{\mathrm{n}}$ and $g_{\mathrm{sc}}$ or $g_{\mathrm{m}}$ were found for the different species of a PFG across water stress treatments, although the quantitative relations were significantly different between PFGs (Supplementary Data Fig. S1).

The $g_{\mathrm{sc}} / g_{\mathrm{m}}$ ratio showed no significant differences between water availability conditions or PFGs ( $p>0.05$ ), while iWUE obs was significantly influenced by drought stress (Table 3). Drought stress improved $\mathrm{iWUE}_{\mathrm{obs}}$ by $25 \%$ compared with non-stress conditions when pooling the data of all plant functional groups (Fig. 3b). The $g_{\mathrm{sc}} / g_{\mathrm{m}}$ ratio of drought-stressed plants $(0.79 \pm 0.11$, $95 \% \mathrm{CI})$ was almost identical to that of non-stressed plants $(0.79 \pm 0.09,95 \% \mathrm{CI})(p>0.05)$ (Fig.3a). The $g_{\mathrm{sd}} / g_{\mathrm{m}}$ ratio of the $\mathrm{EW}(0.87 \pm 0.13,95 \% \mathrm{CI})$ appeared to be higher, but not significantly so, than that of the DW $(0.71 \pm 0.11,95 \% \mathrm{CI})$ and the HB $(0.77 \pm 0.12,95 \% \mathrm{CI})$ PFG. The mean $\mathrm{g}_{\mathrm{sc}} / \mathrm{g}_{\mathrm{m}}$ ratio was $0.79( \pm 0.07,95 \% \mathrm{CI}, \mathrm{n}=198)$ across drought-stress levels and PFGs. There was a significant correlation between $g_{\mathrm{m}}$ and $g_{\mathrm{sc}}$ that was similar for drought-stressed $\left(r^{2}=0.58, n=106\right.$, $p<0.0001$, Fig. 4) and non-stressed conditions $\left(r^{2}=0.20, n=92, p<0.0001\right.$, Fig. 4). When pooling all data of the main dataset to include other long-term treatments, $g_{\mathrm{sc}}$ and $g_{\mathrm{m}}$ were also positively correlated $\left(r^{2}=0.47, n=364, p<0.0001\right)$ with a mean $g_{\text {sc }} / g_{\mathrm{m}}$ of $0.88 \pm 0.06$ (95\%CI) (Supplementary Data Fig. S2).

\section{Predicting iWUE from photosynthetic ${ }^{13} \mathrm{C}$ discrimination $\triangle$}

A value for $g_{\mathrm{sc}} g_{\mathrm{m}}$ of 0.79 was used to compute iWUEmes (Eqn 12) and thus predict iWUE from day-respiration corrected $\Delta\left(\Delta_{\mathrm{P}}\right)$ in seven species in controlled-environment experiments reported in Table 2. $\mathrm{iWUE}_{\text {mes }}$ agreed much better with observed values of $\mathrm{iWUE}_{\mathrm{obs}}$ than $\mathrm{iWUE}_{\text {sim }}$ as shown by the regression analysis (Fig. 5a). This was further supported by the RMSE which was far lower for $\mathrm{iWUE}_{\text {mes }}$ than for $\mathrm{iWUE}_{\text {sim }}$ (Fig. 5). The mean error of $\mathrm{iWUE}_{\mathrm{mes}}\left(5 \mu \mathrm{mol} \mathrm{mol}{ }^{-1}\right)$ was also significantly lower than that of $\mathrm{iWUE}_{\text {sim }}\left(53 \mu \mathrm{mol} \mathrm{mol}^{-1}\right)$. The difference in RMSE between the two models was largest (about $62 \mu \mathrm{mol} \mathrm{mol}^{-1}$ ) in G. max and smallest in H. lanatus and T. aestivum, at only about one half that of G. max. The accuracy of predicted iWUE using iWUEmes thus seemed to vary somewhat between species, likely related to interspecific differences in $g_{\mathrm{sc}} g_{\mathrm{m}}$.

We analyzed the relationship between the measured $g_{\mathrm{m}}$ or $g_{\mathrm{sc}} / g_{\mathrm{m}}$ and $\mathrm{iWUE}$ obs also in the drought-stress dataset and the two independent datasets, where $g_{\mathrm{m}}$ was measured using the online 
$\Delta$ method of Gong et al. $(2015,2018)$. This revealed a weak but statistically significant negative correlation between $g_{\mathrm{m}}$ and $\mathrm{iWUE}_{\mathrm{obs}}$ across drought-stress levels and species $\left(p<0.01, r^{2}<0.1\right.$, Fig. $6 a)$, a correlation that was also confirmed in our experimental datasets $\left(p<0.0001, r^{2}=0.37\right.$, Fig. 6b). We found a significant negative correlation between $g_{\mathrm{sc}} / g_{\mathrm{m}}$ and $\mathrm{iWUE}$ obs in all datasets (Fig. $6 \mathrm{~cd})$. This relation was more robust than the $g_{\mathrm{m}} \mathrm{iWUE}$ obs relationship as was indicated by the higher $r^{2}$, in both the drought-stress dataset $\left(p<0.0001, r^{2}=0.25\right.$, Fig. 6c $)$ and the independent experimental datasets $\left(p<0.0001, r^{2}=0.50\right.$, Fig. 6d). Beyond that, relations between $g_{\mathrm{sc}} g_{\mathrm{m}}$ and $\mathrm{iWUE}_{\mathrm{obs}}$ were statistically identical (i.e. regression parameters were not significantly different) for both datasets.

\section{DISCUSSION}

\section{Including mesophyll conductance in iWUE estimation is critical}

The importance of accounting for $g_{\mathrm{m}}$ in the $\Delta$-iWUE relationship is supported by our model analysis, which illustrates that omitting mesophyll conductance (or the use of iWUE $\mathrm{E}_{\text {sim }}$ which assumes an infinite $g_{\mathrm{m}}$ ) causes a significant overestimation of observed iWUE. Of course, the impact of omitting mesophyll conductance is large when mesophyll conductance is small and affecting $\Delta$ considerably. At a "common" $\Delta$ value of $18 \%$, the iWUE sim model overestimated

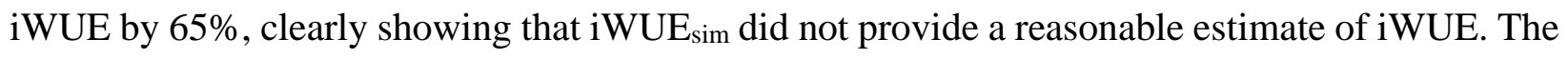
overestimation of iWUE resulting from omission of mesophyll conductance was even greater at a lower $\Delta$, showing that the use of $\mathrm{iWUE}_{\text {sim }}$ is even more problematic under conditions that lead to decreasing $\Delta$. This means, that caution must be taken when comparing iWUE of plants in conditions that lead to divergent $\Delta$, such as contrasting soil water availability, temperature, or transpiration demand when using the $\mathrm{iWUE}_{\text {sim }}$ model.

Quantitative prediction of iWUE is essential to anticipate plant responses to climate change factors like $\mathrm{CO}_{2}$ and precipitation regime (Adams et al., 2019; Soh et al., 2019). Recent studies have shown an increased need to quantify the rate at which iWUE has been changing in different geographical regions (Adams et al., 2019). Here, using iWUEmes to account for the $g_{\mathrm{sc}} / g_{\mathrm{m}}$ ratio seems necessary. By contrast, the impact of respiratory fractionation, boundary layer conductance, and ternary effect on iWUE $E_{\text {mes }}$ values is far less critical. This not only supports assumptions we made to derive $\mathrm{iWUE}_{\text {mes }}$ (in Eqn 12), but also means that comparing crop varieties for $\mathrm{iWUE}_{\text {mes }}$ 
should not be compromised significantly by changes in respiratory metabolism or leaf morphology affecting boundary layer.

An accurate estimation of iWUE is also essential to predict relations between water and carbon fluxes at scales higher than the leaf scale. For instance, combining iWUE estimates from the ${ }^{13} \mathrm{C}$ discrimination and transpiration flux inferred from sap flow has been used to quantify photosynthesis of forest canopies (Klein et al., 2016). The isotope fractionation can be estimated using the $\delta^{13} \mathrm{C}$ value of either bulk organic matter or carbohydrates (via compound-specific $\delta^{13} \mathrm{C}$ analysis of sugars). The $\delta^{13} \mathrm{C}$ in sugars is believed to be better proxy for iWUE because it reflects recent photosynthetic assimilation and is less influenced by post-photosynthetic fractionation processes (Hobbie \& Werner, 2004; Badeck et al., 2005). Smith et al. (2016) showed that using the $\delta^{13} \mathrm{C}$ of leaf and phloem carbohydrates improved the precision of iWUE estimations, as compared to using the $\delta^{13} \mathrm{C}$ value of bulk soluble carbon. However, both methods overestimated iWUE when iWUEsim was used. We used their data (Smith et al., 2016) and calculated iWUEmes using a $g_{\mathrm{sc}} g_{\mathrm{m}}$ of 0.79 , with the value of $\Delta$ obtained from individual carbohydrates (i.e. sucrose, glucose, and fructose). This significantly reduced the error in predicted iWUE (Fig. S3). That is, neglecting the impact of $g_{\mathrm{m}}$ also overestimates considerably iWUE calculated from the $\delta^{13} \mathrm{C}$ value of individual carbohydrates.

\section{Parameterization of $i W U E_{\text {mes }}$ calculation}

As shown by Eqn 11 or 12, calculating $\mathrm{iWUE}_{\mathrm{mes}}$ from $\Delta$ requires the knowledge of the $g_{\mathrm{sc}} / g_{\mathrm{m}}$ ratio. Our study suggests that a value of $g_{\mathrm{sc}} / g_{\mathrm{m}}$ of 0.79 can be applied broadly. In fact, that ratio did not seem to be influenced by drought stress or plant functional groups in the global dataset. Using such

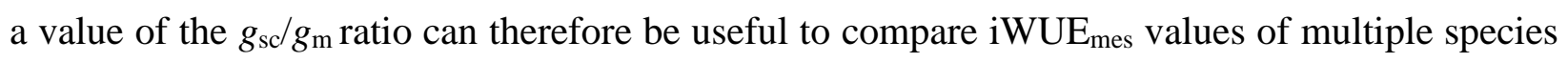
grown under varying soil water conditions, particularly if there is no direct information on mesophyll conductance. The use of a value of 0.79 is further supported by our independent experimental data of seven species (Fig. 5). It is worth noting that even the use of a constant value of 0.79 does not simply change the scale of iWUE values by a proportionality constant, because the term associated with $g_{\mathrm{m}}$ in $\mathrm{iWUE}_{\mathrm{mes}}$ is an additive term in the denominator (Eqn 12). The apparent insensitivity of the $g_{\mathrm{sc}} / g_{\mathrm{m}}$ ratio to drought relates to the similar sensitivity of $g_{\mathrm{sc}}$ and $g_{\mathrm{m}}$ to long-term water stress, as both were reduced by about $50 \%$ across plant functional groups. In other words, our results do not directly support the hypothesis of a lower sensitivity of $g_{\mathrm{m}}$ to drought 
stress compared to $g_{\mathrm{sc}}$, to help maintaining leaf carbon gain (Cano et al., 2014). Also, $A_{\mathrm{n}}$ appeared to decline less than $g_{\mathrm{sw}}$, leading to an increased iWUE under sustained drought-stress, as we previously found in the field (Gong et al., 2011). In addition, our compilation of observations on multiple species shows a negative correlation between $g_{\mathrm{m}}$ and iWUE $\mathrm{ibs}_{\mathrm{s}}$ across drought-stress levels, challenging the common assumption that a high $g_{\mathrm{m}}$ is beneficial to water-use during photosynthesis (Barbour et al., 2010; Flexas et al., 2013; Barbour \& Kaiser, 2016). In other words, our survey suggests that increased iWUE may not necessarily be associated with high $g_{\mathrm{m}}$.

Although a common $g_{s} / g_{m}$ value of 0.79 seems to be an acceptable compromise when information on mesophyll conductances is not available, it is certainly desirable to parameterize $\mathrm{iWUE}_{\text {mes }}$ with proper experimental values in order to compute precise intrinsic water use efficiency values. In fact, we found a significant, negative relationship between $\mathrm{iWUE}$ obs and $g_{\mathrm{sc}} / g_{\mathrm{m}}$ across a large range of species (Fig. 6). In addition, $g_{\mathrm{sc}} / g_{\mathrm{m}}$ explained a higher proportion of variation in iWUE ${ }_{\text {obs }}$ compared to $g_{\mathrm{m}}$ alone, as expected from Eqn 12. Therefore, $g_{\mathrm{sc}} / g_{\mathrm{m}}$ contributed to explaining better the observed interspecific difference in iWUE $_{\text {obs. }}$ That is also probably the case between varieties within the same species, and thus the $g_{\mathrm{sc}} / g_{\mathrm{m}}$ ratio should be considered in breeding programs targeting water-use efficiency.

We nevertheless recognize that variations in $g_{\mathrm{sc}} / g_{\mathrm{m}}$ amongst functionally similar species or between studies is the main challenge in the use of iWUEmes. Current studies show that responses of $g_{\mathrm{m}}$ to environmental factors are highly complex and such factors include $\mathrm{CO}_{2}$ (Flexas et al., 2007), temperature (von Caemmerer \& Evans, 2013; Shrestha et al., 2019) and VPD (Loucos et al., 2017, Stangl et al., 2019). Up to now, variations in $g_{\mathrm{m}}$ cannot be easily related to anatomical features and it is believed that biochemical processes (e.g. facilitated diffusion by carbonic anhydrase or aquaporins) are involved (Flexas et al., 2008) although controversial results have been obtained (Perez-Martin et al., 2014; Kromdijk et al., 2020). It is also worth noting that observed variations in $g_{\mathrm{m}}$ could be related to the methods used for measurements. Some authors questioned the robustness of current observed values of $g_{\mathrm{m}}$ (Tholen et al., 2012; Sun et al., 2014b), because current methods extract $g_{\mathrm{m}}$ from a residual photosynthetic component after other processes have been accounted for, meaning that all errors (artifacts) accumulate in the estimate of $g_{\mathrm{m}}$ (Pons et al., 2009). For example, Gong et al. (2015) demonstrated that $g_{\mathrm{m}}$ estimates can be strongly influenced by diffusive leaks and isotopic disequilibria between respiration and photosynthesis when $g_{m}$ is computed from non-corrected online $\Delta$ values. The contribution of the apparent isotopic 
fractionation by day respiration could easily be misquantified if carbon reserves are respired instead of current photosynthates, thus causing errors in $g_{\mathrm{m}}$ estimates (Gong et al., 2015; Tcherkez et al., 2017; Barbour et al., 2017; Busch et al., 2020). The use of iWUEmes effectively provides much more accurate iWUE values than $\mathrm{iWUE}_{\text {sim, }}$, but might be associated with an error (e.g. for species with a different $g_{\mathrm{sc}} / g_{\mathrm{m}}$ ratio) if the 'standard' $0.79 g_{\mathrm{sd}} / g_{\mathrm{m}}$ value is used. Certainly, in mechanistic studies of the controls of iWUE in a given species it is warranted to examine environmental effects on relationships between $g_{\mathrm{sc}}$ and $g_{\mathrm{m}}$ with experimental detail.

\section{Perspectives}

Our analysis shows that the expression of $\mathrm{iWUE}_{\mathrm{mes}}$ that accounts for mesophyll conductance (Eqn 12) can be used to provide better estimates of intrinsic water use efficiency. Together with an observation-based $g_{\mathrm{sc}} / g_{\mathrm{m}}$ ratio, it can be used to reanalyze, adjust or correct published iWUE $\mathrm{E}_{\mathrm{sim}}$ data for which measurements of $g_{\mathrm{m}}$ are unavailable. This has far reaching importance, as $g_{\mathrm{m}}$ is a key parameter for most of the models of leaf photosynthesis or carbon cycling, but is often poorly represented in them (Tholen et al., 2012; Sun et al., 2014b). Assuming an infinite $g_{\mathrm{m}}$ leads to an overestimation of global gross primary production by about $16 \%$ by earth system models (Sun et $a l ., 2014 \mathrm{a})$. Scaling of $g_{\mathrm{m}}$ to $g_{\mathrm{sc}}$ is potentially a useful way to reduce the error related to $g_{\mathrm{m}}$ in such models. Our study also examined potential differences in $g_{\mathrm{sc}} / g_{\mathrm{m}}$ ratios across long-term droughtstress treatments and plant functional groups and showed that $g_{\mathrm{sc}} / g_{\mathrm{m}}$ has rather similar values such that an average value of 0.79 in the $\mathrm{iWUE}_{\text {mes }}$ model works well to provide more realistic iWUE values. However, in an effort to compare and select varieties based on water use efficiency, genotypic variation in $g_{\mathrm{sc}} / g_{\mathrm{m}}$ should not be overlooked. That is, the effect of mesophyll conductance (relative to that of stomatal conductance) must be accounted for to provide reliable estimates of iWUE based on carbon isotopes. This is particularly true in crop species where mesophyll conductance contributes significantly to photosynthetic limitations such as $V$. faba, $G$. max and $P$. vulgaris in this study.

\section{ACKNOWLEDGMENTS}

This work was supported by the National Natural Science Foundation of China (NSFC 31870377), the Guangdong Natural Science Foundation (2018A030313450) and the Deutsche Forschungsgemeinschaft (SCHN 557/7-1 and SCHN 557/9-1). 


\section{AUTHOR CONTRIBUTIONS}

X.Y.G. designed and planned the research; G.T. proposed the iWUEcom model and the framework of sensitivity analyses; W.T.M. performed the literature survey and data analyses; W.T.M., X.M.W and X.Y.G. wrote the first draft, and all authors discussed the results and implications and contributed to the revision.

\section{REFERENCES}

Adams MA, Buckley TN, Turnbull TL. 2019. Rainfall drives variation in rates of change in intrinsic water use efficiency of tropical forests. Nature Communications 10: 3661.

Adams MA, Buckley TN, Turnbull TL. 2020. Diminishing $\mathrm{CO}_{2}$-driven gains in water-use efficiency of global forests. Nature Climate Change 10: 466-471.

Badeck FW, Tcherkez G, Nogues S, Piel C, Ghashghaie J. 2005. Post-photosynthetic fractionation of stable carbon isotopes between plant organs - a widespread phenomenon. Rapid Communications in Mass Spectrometry 19: 1381-1391.

Barbosa ICR, Köhler IH, Auerswald K, Lüps P, Schnyder H. 2010. Last-century changes of alpine grassland water-use efficiency: a reconstruction through carbon isotope analysis of a timeseries of Capra ibex horns. Global Change Biology 16: 1171-1180.

Barbour MM, Kaiser BN. 2016. The response of mesophyll conductance to nitrogen and water availability differs between wheat genotypes. Plant Science 251: 119-127.

Barbour MM, Ryazanova S, Tcherkez G. 2017. Respiratory effects on the carbon isotope discrimination near the compensation point. In: Tcherkez G, J. Ghashghaie (eds.), Plant Respiration: Metabolic Fluxes and Carbon Balance, Advances in Photosynthesis and Respiration 43, Springer 144-158

Barbour MM, Warren CR, Farquhar GD, Forrester G, Brown H. 2010. Variability in mesophyll conductance between barley genotypes, and effects on transpiration efficiency and carbon isotope discrimination. Plant, Cell \& Environment 33: 1176-1185.

Betts RA, Boucher O, Collins M, Cox PM, Falloon PD, Gedney N, Hemming DL, Huntingford C, Jones CD, Sexton DMH, et al. 2007. Projected increase in continental runoff due to plant responses to increasing carbon dioxide. Nature 448: 1037-1041. 
Bowling DR, Pataki DE, Randerson JT. 2008. Carbon isotopes in terrestrial ecosystem pools and $\mathrm{CO}_{2}$ fluxes. New Phytologist 178: 24-40.

Brooks A, Farquhar GD. 1985. Effect of temperature on the $\mathrm{CO}_{2} / \mathrm{O}_{2}$ specificity of ribulose-1,5bisphosphate carboxylase/oxygenase and the rate of respiration in the light. Planta 165: 397-406.

Busch FA, Holloway-Phillips M, Stuart-Williams H, Farquhar GD. 2020. Revisiting carbon isotope discrimination in $\mathrm{C}_{3}$ plants shows respiration rules when photosynthesis is low. Nature Plants 6: 245-258.

Cano FJ, Lopez R, Warren CR. 2014. Implications of the mesophyll conductance to $\mathrm{CO}_{2}$ for photosynthesis and water-use efficiency during long-term water stress and recovery in two contrasting Eucalyptus species. Plant, Cell \& Environment 37: 2470-2490.

Cornwell WK, Wright IJ, Turner J, Maire V, Barbour MM, Cernusak LA, Dawson T, Ellsworth D, Farquhar GD, Griffiths H, et al. 2018. Climate and soils together regulate photosynthetic carbon isotope discrimination within $\mathrm{C}_{3}$ plants worldwide. Global Ecology and Biogeography 27: 1056-1067.

Douthe C, Dreyer E, Epron D, Warren CR. 2011. Mesophyll conductance to $\mathrm{CO}_{2}$, assessed from online TDL-AS records of ${ }^{13} \mathrm{CO}_{2}$ discrimination, displays small but significant short-term responses to $\mathrm{CO}_{2}$ and irradiance in Eucalyptus seedlings. Journal of Experimental Botany 62: 5335-5346.

Evans JR, Sharkey TD, Berry JA, Farquhar GD. 1986. Carbon isotope discrimination measured concurrently with gas exchange to investigate $\mathrm{CO}_{2}$ diffusion in leaves of higher plants. Australian Journal of Plant Physiology 13: 281-292.

Evans JR, Von Caemmerer S. 2013. Temperature response of carbon isotope discrimination and mesophyll conductance in tobacco. Plant, Cell \& Environment 36: 745-756.

Farquhar GD, Ehleringer JR, Hubick KT. 1989. Carbon isotope discrimination and photosynthesis. Annual Review of Plant Physiology and Plant Molecular Biology 40: 503-537.

Farquhar GD, O'Leary MH, Berry JA. 1982. On the relationship between carbon isotope discrimination and the intercellular carbon dioxide concentration in leaves. Australian Journal of Plant Physiology 9: 121-137.

Farquhar GD, Richards RA. 1984. Isotopic composition of plant carbon correlates with water-use efficiency of wheat genotypes. Australian Journal of Plant Physiology 11: 539-552. 
Flexas J, Barbour MM, Brendel O, Cabrera HM, Carriquí M, Díaz-Espejo A, Douthe C, Dreyer E, Ferrio JP, Gago J, et al. 2012. Mesophyll diffusion conductance to $\mathrm{CO}_{2}$ : an unappreciated central player in photosynthesis. Plant Science 193-194: 70-84.

Flexas J, Diaz-Espejo A, Galmes J, Kaldenhoff R, Medrano H, Ribas-Carbo M. 2007. Rapid variations of mesophyll conductance in response to changes in $\mathrm{CO}_{2}$ concentration around leaves. Plant, Cell \& Environment 30: 1284-1298.

Flexas J, Niinemets, Ü, Gallé A, Barbour MM, Centritto M, Diaz-Espejo A, Douthe C, Galmés J, Ribas-Carbo M, Rodriguez PL, et al. 2013. Diffusional conductances to $\mathrm{CO}_{2}$ as a target for increasing photosynthesis and photosynthetic water-use efficiency. Photosynthsis Research 117: 45-59.

Flexas J, Ribas-Carbo M, Diaz-Espejo A, Galmes J, Medrano H. 2008. Mesophyll conductance to $\mathrm{CO}_{2}$ : current knowledge and future prospects. Plant, Cell \& Environment 31: 602-621.

Franks PJ, Adams MA, Amthor JS, Barbour MM, Berry JA, Ellsworth DS, Farquhar GD, Ghannoum O, Lloyd J, McDowell N, et al. 2013. Sensitivity of plants to changing atmospheric $\mathrm{CO}_{2}$ concentration: from the geological past to the next century. New Phytologist 197: 1077-1094.

Galmes J, Medrano H, Flexas J. 2007. Photosynthetic limitations in response to water stress and recovery in Mediterranean plants with different growth forms. New Phytologist 175: 81-93.

Gauthier PPG, Battle MO, Griffin KL, Bender ML. 2018. Measurement of gross photosynthesis, respiration in the light, and mesophyll conductance using $\mathrm{H}_{2}{ }^{18} \mathrm{O}$ labeling. Plant Physiology 177(1): 62-74.

Gong XY, Chen Q, Lin S, Brueck H, Dittert K, Taube F, Schnyder H. 2011. Tradeoffs between nitrogen- and water-use efficiency in dominant species of the semiarid steppe of Inner Mongolia. Plant and Soil 340: 227-238.

Gong XY, Schäufele R, Feneis W, Schnyder H. 2015. ${ }^{13} \mathrm{CO}_{2} /{ }^{12} \mathrm{CO}_{2}$ exchange fluxes in a clamp-on leaf cuvette: disentangling artefacts and flux components. Plant, Cell \& Environment 38: 24172432.

Gong XY, Schäufele R, Lehmeier CA, Tcherkez G, Schnyder H. 2017. Atmospheric $\mathrm{CO}_{2}$ mole fraction affects stand-scale carbon use efficiency of sunflower by stimulating respiration in light. Plant, Cell \& Environment 40: 401-412. 
Gong XY, Tcherkez G, Wenig J, Schäufele R, Schnyder H. 2018. Determination of leaf respiration in the light: comparison between an isotopic disequilibrium method and the Laisk method. New Phytologist 218: 1371-1382.

Harley PC, Loreto F, Dimarco G, Sharkey TD. 1992. Theoretical considerations when estimating the mesophyll conductance to $\mathrm{CO}_{2}$ flux by analysis of the response of photosynthesis to $\mathrm{CO}_{2}$. Plant Physiology 98: 1429-1436.

Hobbie EA, Werner RA. 2004. Intramolecular, compound-specific, and bulk carbon isotope patterns in $\mathrm{C}_{3}$ and $\mathrm{C}_{4}$ plants: a review and synthesis. New Phytologist 161: 371-385.

Köhler IH, Macdonald A, Schnyder H. 2012. Nutrient supply enhanced the increase in intrinsic water - use efficiency of a temperate seminatural grassland in the last century. Global Change Biology 18: 3367-3376.

Klein T, Rotenberg E, Tatarinov F, Yakir D. 2016. Association between sap flow-derived and eddy covariance-derived measurements of forest canopy $\mathrm{CO}_{2}$ uptake. New Phytologist 209: 436446.

Kooperman GJ, Chen Y, Hoffman FM, Koven CD, Lindsay K, Pritchard MS, Swann ALS, Randerson JT. 2018. Forest response to rising $\mathrm{CO}_{2}$ drives zonally asymmetric rainfall change over tropical land. Nature Climate Change 8: 434-440.

Kromdijk J, Głowacka K, Long SP. 2020. Photosynthetic efficiency and mesophyll conductance are unaffected in Arabidopsis thaliana aquaporin knock-out lines. Journal of Experimental Botany 71: 318-329.

Lin YS, Medlyn BE, Duursma RA, Prentice IC, Wang H, Baig S, Eamus D, de Dios Victor R, Mitchell P, Ellsworth DS, et al. 2015. Optimal stomatal behaviour around the world. Nature Climate Change 5: 459-464.

Loucos KE, Simonin KA, Barbour MM. 2017. Leaf hydraulic conductance and mesophyll conductance are not closely related within a single species. Plant, Cell \& Environment 40: 203215.

Perez-Martin A, Michelazzo C, Torres-Ruiz JM, Flexas J, Fernandez JE, Sebastiani L, DiazEspejo A. 2014. Regulation of photosynthesis and stomatal and mesophyll conductance under water stress and recovery in olive trees: correlation with gene expression of carbonic anhydrase and aquaporins. Journal of Experimental Botany 65: 3143-3156. 
Pons TL, Flexas J, von Caemmerer S, Evans JR, Genty B, Ribas-Carbo M, Brugnoli E. 2009. Estimating mesophyll conductance to $\mathrm{CO}_{2}$ : methodology, potential errors, and recommendations. Journal of Experimental Botany 60: 2217-2234.

Rebetzke GJ, Condon AG, Farquhar GD, Appels R, Richards RA. 2008. Quantitative trait loci for carbon isotope discrimination are repeatable across environments and wheat mapping populations. Theoretical and Applied Genetics 118(1): 123-137.

Schnyder H, Schäufele R, Lötscher M, Gebbing T. 2003. Disentangling $\mathrm{CO}_{2}$ fluxes: direct measurements of mesocosm-scale natural abundance ${ }^{13} \mathrm{CO}_{2} /{ }^{12} \mathrm{CO}_{2}$ gas exchange, ${ }^{13} \mathrm{C}$ discrimination, and labelling of $\mathrm{CO}_{2}$ exchange flux components in controlled environments. Plant, Cell \& Environment 26: 1863-1874.

Seibt U, Rajabi A, Griffiths H, Berry JA. 2008. Carbon isotopes and water use efficiency: sense and sensitivity. Oecologia 155: 441-454.

Shrestha A, Song X, Barbour MM. 2019. The temperature response of mesophyll conductance, and its component conductances, varies between species and genotypes. Photosynthesis Research 141: 65-82.

Smith M, Wild B, Richter A, Simonin K, Merchant A. 2016. Carbon isotope composition of carbohydrates and polyols in leaf and phloem sap of phaseolus vulgaris L. influences predictions of plant water use efficiency. Plant \& Cell Physiology 57: 1756-1766.

Soh WK, Yiotis C, Murray M, Parnell A, Wright IJ, Spicer RA, Lawson T, Caballero R, McElwain JC. 2019. Rising $\mathrm{CO}_{2}$ drives divergence in water use efficiency of evergreen and deciduous plants. Science Advances 5: eaax7906.

Stangl ZR, Tarvainen L, Wallin G, Ubierna N, Räntfors M, Marshall JD. 2019. Diurnal variation in mesophyll conductance and its influence on modelled water-use efficiency in a mature boreal Pinus sylvestris stand. Photosynthesis Research 141: 53-63.

Sun Y, Gu LH, Dickinson RE, Norby RJ, Pallardy SG, Hoffman FM. 2014a. Impact of mesophyll diffusion on estimated global land $\mathrm{CO}_{2}$ fertilization. Proceedings of the National Academy of Sciences of the United States of America 111: 15774-15779.

Sun Y, Gu LH, Dickinson RE, Pallardy SG, Baker J, Cao YH, Damatta FM, Dong XJ, Ellsworth D, Van Goethem D, et al. 2014b. Asymmetrical effects of mesophyll conductance on fundamental photosynthetic parameters and their relationships estimated from leaf gas exchange measurements. Plant, Cell \& Environment 37: 978-994. 
Tazoe Y, Von Caemmerer S, Estavillo GM, Evans JR. 2011. Using tunable diode laser spectroscopy to measure carbon isotope discrimination and mesophyll conductance to $\mathrm{CO}_{2}$ diffusion dynamically at different $\mathrm{CO}_{2}$ concentrations. Plant, Cell \& Environment 34: 580-591.

Tcherkez G, Gauthier P, Buckley TN, Busch FA, Barbour MM, Bruhn D, Heskel MA, Gong XY, Crous KY, Griffin K, et al. 2017. Leaf day respiration: low $\mathrm{CO}_{2}$ flux but high significance for metabolism and carbon balance. New Phytologist 216(4): 986-1001.

Tcherkez G, Mauve C, Lamothe M, Le Bras C, Grapin A. 2011. The ${ }^{13} \mathrm{C} /{ }^{12} \mathrm{C}$ isotopic signal of day-respired $\mathrm{CO}_{2}$ in variegated leaves of Pelargonium $\times$ hortorum. Plant, Cell \& Environment 34: 270-283.

Tholen D, Ethier G, Genty B, Pepin S, Zhu XG. 2012. Variable mesophyll conductance revisited: theoretical background and experimental implications. Plant, Cell \& Environment 35: 2087-2103.

Tosens T, Niinemets Ü, Westoby M, Wright IJ. 2012. Anatomical basis of variation in mesophyll resistance in eastern Australian sclerophylls: news of a long and winding path. Journal of Experimental Botany 63: 5105-5119.

Ubierna N, Holloway-Phillips MM, Farquhar GD. 2018. Using stable carbon isotopes to study $\mathrm{C}_{3}$ and $\mathrm{C}_{4}$ photosynthesis: models and calculations. Photosynthesis: Springer, 155-196.

van der Sleen P, Groenendijk P, Vlam M, Anten NPR, Boom A, Bongers F, Pons TL, Terburg G, Zuidema PA. 2015. No growth stimulation of tropical trees by 150 years of $\mathrm{CO}_{2}$ fertilization but water-use efficiency increased. Nature Geoscience 8: 24-28.

Warren CR. 2008. Soil water deficits decrease the internal conductance to $\mathrm{CO}_{2}$ transfer but atmospheric water deficits do not. Journal of Experimental Botany 59: 327-334.

Warren CR, Aranda I, Cano FJ. 2011. Responses to water stress of gas exchange and metabolites in Eucalyptus and Acacia spp. Plant, Cell \& Environment 34: 1609-1629.

Wittmer MHOM, Auerswald K, Bai YF, Schäufele R, Schnyder H. 2010. Changes in the abundance of $\mathrm{C}_{3} / \mathrm{C}_{4}$ species of Inner Mongolia grassland: evidence from isotopic composition of soil and vegetation. Global Change Biology 16: 605-616.

Yamori W, Noguchi K, Hanba YT, Terashima I. 2006. Effects of internal conductance on the temperature dependence of the photosynthetic rate in spinach leaves from contrasting growth temperatures. Plant \& Cell Physiology 47: 1069-1080. 
bioRxiv preprint doi: https://doi.org/10.1101/2020.07.06.188920; this version posted July 6, 2020. The copyright holder for this preprint (which was not certified by peer review) is the author/funder. All rights reserved. No reuse allowed without permission.

Yang Z, Liu J, Tischer SV, Christmann A, Windisch W, Schnyder H, Grill E. 2016.

Leveraging abscisic acid receptors for efficient water use in Arabidopsis. Proceedings of the National Academy of Sciences 113(24): 6791-6796. 


\section{Tables and Figures}

Table 1. Definitions of abbreviations used for intrinsic water-use efficiency in this paper.

\begin{tabular}{|c|c|}
\hline Abbreviations & Definition \\
\hline iWUE & Generic term for intrinsic water-use efficiency \\
\hline iWUE $E_{o b s}$ & $\begin{array}{l}\text { Observed value of intrinsic water use efficiency using gas } \\
\text { exchange }\left(A_{\mathrm{n}} / g_{\mathrm{sw}}\right)\end{array}$ \\
\hline $\mathrm{iWUE}_{\text {sim }}$ & $\begin{array}{l}\text { Predicted intrinsic water-use efficiency using the simplified } \\
\text { model of }{ }^{12} \mathrm{C} /{ }^{13} \mathrm{C} \text { discrimination (Eqn } 2 \text { ) }\end{array}$ \\
\hline $\mathrm{iWUE}$ mes & $\begin{array}{l}\text { Predicted intrinsic water-use efficiency using the model of } \\
{ }^{12} \mathrm{C} /{ }^{13} \mathrm{C} \text { discrimination accounting for mesophyll conductance } \\
\text { but not boundary layer conductance, ternary effects nor day } \\
\text { respiration (Eqn 12) }\end{array}$ \\
\hline $\mathrm{iWUE}_{\mathrm{com}}$ & $\begin{array}{l}\text { Predicted intrinsic water used efficiency using the model of } \\
{ }^{12} \mathrm{C} /{ }^{13} \mathrm{C} \text { discrimination accounting for all effects, including } \\
\text { mesophyll conductance, ternary effects and day respiration } \\
\text { (Eqn 10) }\end{array}$ \\
\hline $\mathrm{iWUE}_{\text {com }}^{*}$ & $\begin{array}{l}\text { Predicted intrinsic water used efficiency using the model of } \\
{ }^{12} \mathrm{C} /{ }^{13} \mathrm{C} \text { discrimination accounting for all effects, including } \\
\text { mesophyll conductance, ternary effects, boundary layer } \\
\text { conductance and day respiration, and assuming that the } \\
\text { definition of iWUE also includes boundary layer conductance } \\
\text { in the denominator (Eqn 8) }\end{array}$ \\
\hline
\end{tabular}


Table 2 Overview of the two experimental datasets of $\Delta_{\text {obs }}$ in this study

\begin{tabular}{|c|c|c|}
\hline Source & Gong et al. (2015) & Gong et al. (2018) \\
\hline Plant species & Holcus lanatus & $\begin{array}{l}\text { Hordeum vulgare, Triticum } \\
\text { aestivum, Ricinus communis, } \\
\text { Phaseolus vulgaris, Glycine } \\
\text { max, Vicia faba }\end{array}$ \\
\hline Leaf types & $\begin{array}{l}\text { Fully expanded young } \\
\text { leaves }\end{array}$ & Fully expanded young leaves \\
\hline Growth condition & $\begin{array}{l}\text { Growth chamber, } \\
\text { non-stressed condition }\end{array}$ & $\begin{array}{l}\text { Growth chamber, } \\
\text { non-stressed condition }\end{array}$ \\
\hline \multirow{3}{*}{$\begin{array}{l}\text { Measurement } \\
\text { condition }\end{array}$} & PPFD: $1600 \mu \mathrm{mol} \mathrm{m}{ }^{-2} \mathrm{~s}^{-1}$ & PPFD: $700 \mu \mathrm{mol} \mathrm{m}{ }^{-2} \mathrm{~s}^{-1}$ \\
\hline & Leaf temperature: $25^{\circ} \mathrm{C}$; & Leaf temperature, $23^{\circ} \mathrm{C}$ \\
\hline & {$\left[\mathrm{CO}_{2}\right]: 390$ ppm; rH: 70\% } & {$\left[\mathrm{CO}_{2}\right]: 390$ ppm; rH: 70\% } \\
\hline iWUE & Directly measured & Directly measured \\
\hline Diffusive leak & Quantified and corrected & Quantified and corrected \\
\hline $\begin{array}{l}\text { Contribution of day } \\
\text { respiration to } \Delta_{\text {obs }}\end{array}$ & Quantified and corrected & Quantified and corrected \\
\hline
\end{tabular}


1 Table 3 ANOVA tests for $A_{\mathrm{n}}, g_{\mathrm{sc}}, g_{\mathrm{m}}, g_{\mathrm{sc}} g_{\mathrm{m}}$, and $\mathrm{iWUE}_{\mathrm{obs}}$ using a general linear model. Data are 2 square root transformed to improve the normality before ANOVA tests. Significant effects are 3 shown in bold $(p<0.05)$

\begin{tabular}{llllllllllll}
\hline Source & & \multicolumn{2}{c}{$A_{\mathrm{n}}$} & \multicolumn{2}{c}{$g_{\mathrm{sc}}$} & \multicolumn{2}{c}{$g_{\mathrm{m}}$} & \multicolumn{2}{c}{$g_{\mathrm{sc}} / g_{\mathrm{m}}$} & \multicolumn{2}{c}{ iWUE $_{\mathrm{obs}}$} \\
\cline { 3 - 12 } & df & $F$ & $P$ & $F$ & $P$ & $F$ & $P$ & $F$ & $P$ & $F$ & $P$ \\
\hline $\begin{array}{l}\text { Drought } \\
\text { stress }\end{array}$ & 1 & 101.44 & $\mathbf{0 . 0 0 0}$ & 105.43 & $\mathbf{0 . 0 0 0}$ & 56.13 & $\mathbf{0 . 0 0 0}$ & 0.004 & 0.949 & 9.91 & $\mathbf{0 . 0 0 2}$ \\
PFG & 2 & 50.85 & $\mathbf{0 . 0 0 0}$ & 31.33 & $\mathbf{0 . 0 0 0}$ & 30.61 & $\mathbf{0 . 0 0 0}$ & 1.530 & 0.219 & 0.48 & 0.617 \\
W*PFG & 2 & 3.85 & $\mathbf{0 . 0 2 3}$ & 6.70 & $\mathbf{0 . 0 0 2}$ & 4.75 & $\mathbf{0 . 0 1 0}$ & 0.199 & 0.820 & 0.99 & 0.374 \\
\hline
\end{tabular}

4 

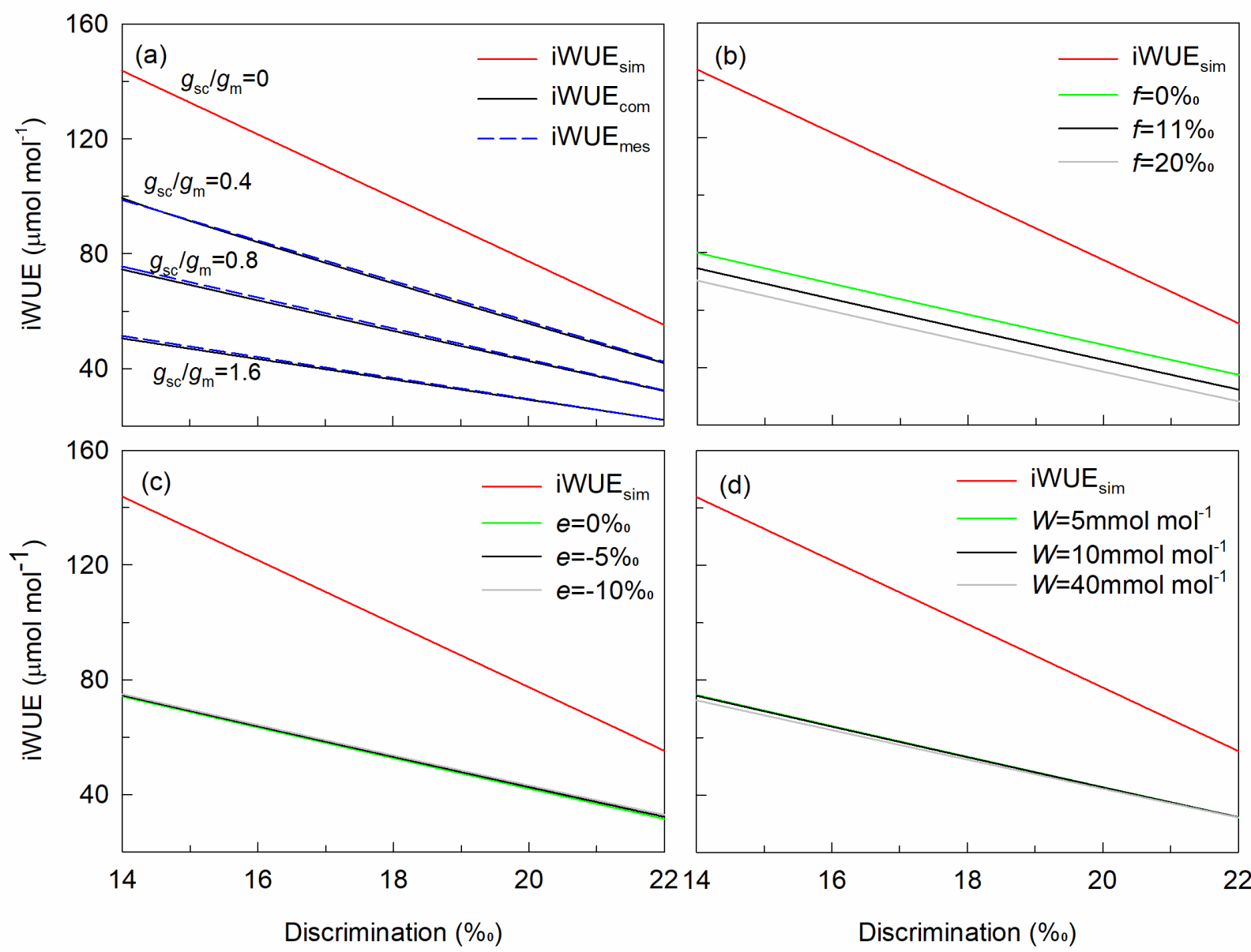

5

6 Fig. 1 Sensitivity test of iWUE prediction by the $\mathrm{iWUE}_{\mathrm{com}}$ model and the $\mathrm{iWUE}_{\mathrm{mes}}$ model as

7 affected by $g_{\mathrm{sc}} / g_{\mathrm{m}}$ ratios (a) and the influence of photorespiratory fractionation (b), mitochondrial

8 respiratory fractionation (c) and leaf-to-air vapor concentration difference $\left(W, \mathrm{mmol} \mathrm{mol}^{-1}, \mathrm{~d}\right)$ on

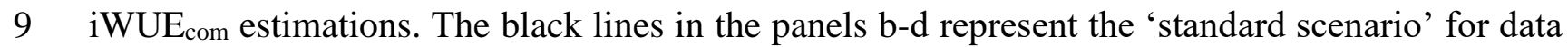

10 simulation with $g_{\mathrm{sc}} g_{\mathrm{m}}=0.8, f=11 \%, e=-5 \%$, and $W=10 \mathrm{mmol} \mathrm{mol}^{-1}$. The values of parameters for

11 simulations were shown in Table S1. 


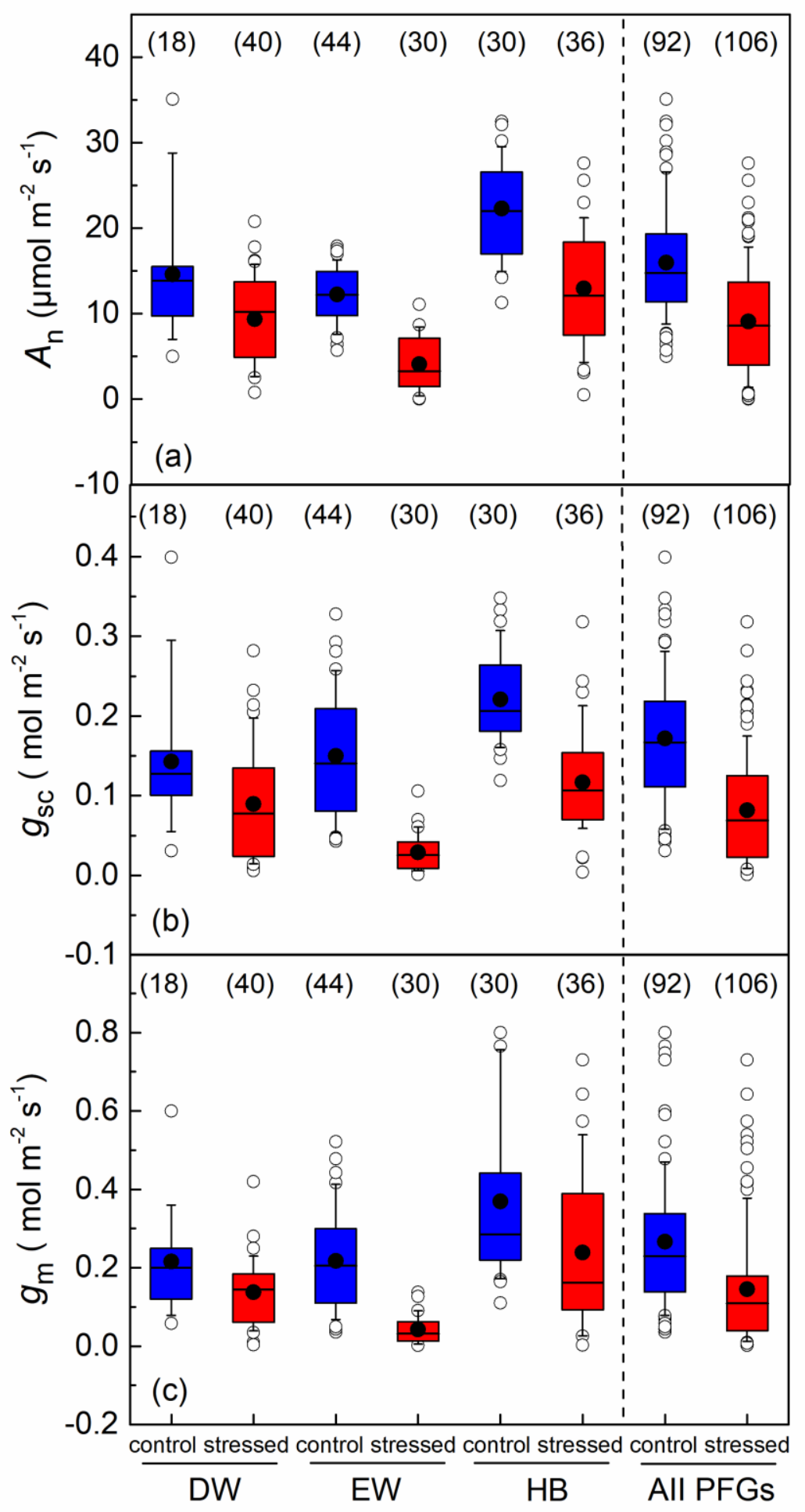

13 Fig. $\left.2 A_{\mathrm{n}} \mathrm{a}\right), g_{\mathrm{sc}} \mathrm{b}$ ) and $g_{\mathrm{m}} \mathrm{c}$ ) across drought-stress levels and plant functional groups (PFGs: DW,

14 deciduous and semi-deciduous woody species; EW evergreen woody species; and HB,

15 herbaceous species). Data collection of different species under non-stressed (blue boxes) or 
16 water-stressed conditions (red boxes). Boxplots show median (center line), mean (black dot),

17 inter-quartile range, 10-90\% range (whiskers), and outliers (open circles). Numbers in brackets

18 are the number of observations. Data are from the following references: Bongi et al. (1989),

19 Delfine et al. (2001, 2005), Flexas et al. (2002), Galmes et al. (2007), Miyzawa et al. (2008),

20 Barbour and Kaiser (2016), Brilli et al. (2013), Cano et al. (2013, 2014), Centritto et al. (2009),

21 Ferrio et al. (2012), Perez-Martin et al. (2009, 2014), Warren et al. (2008, 2011). 


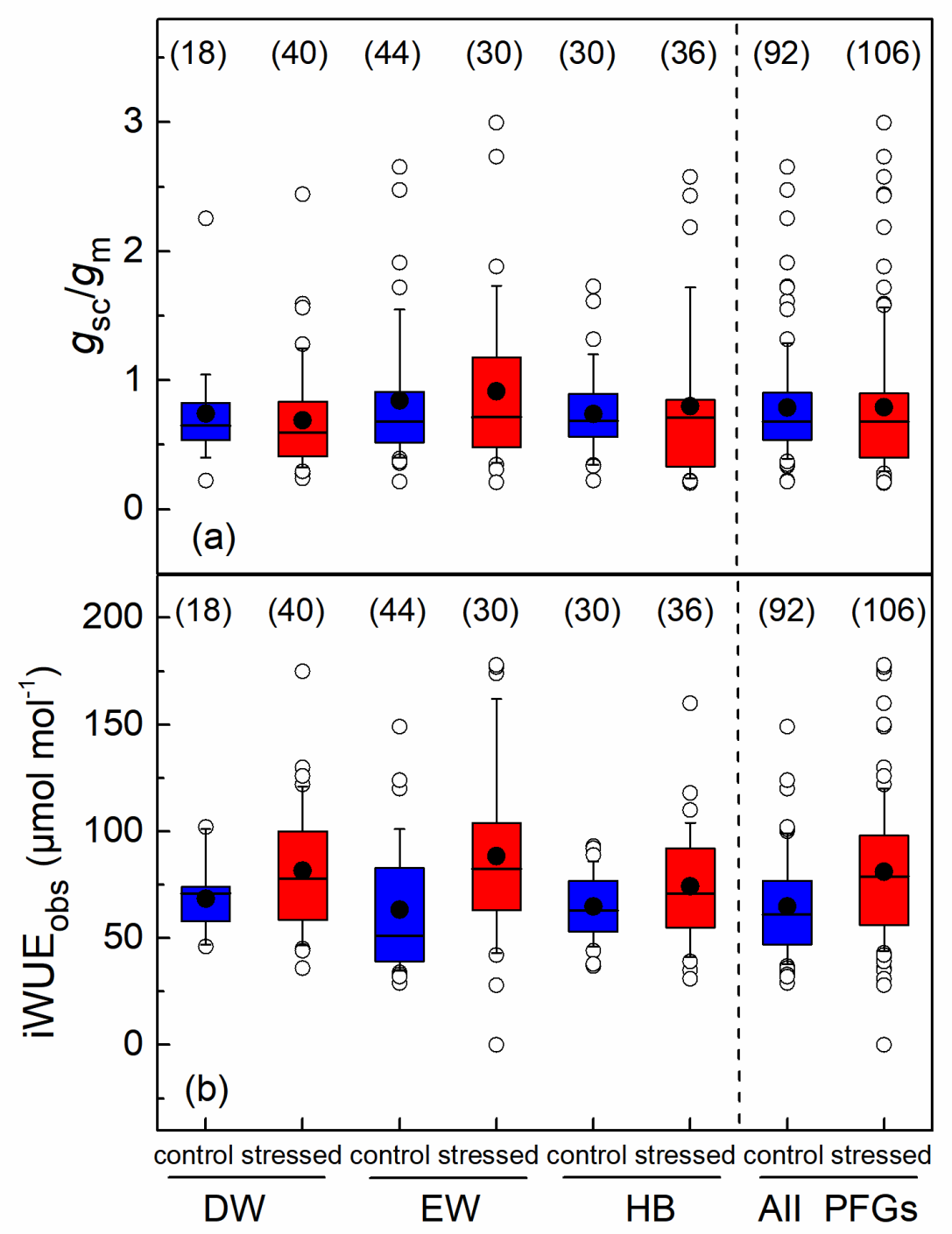

23 Fig. $3 g_{\mathrm{sc}} / g_{\mathrm{m}}$ a) and iWUE ${ }_{\mathrm{obs}}$ b) across drought treatments and plant functional groups (PFGs: DW, 24 deciduous and semi-deciduous woody species; EW evergreen woody species; and HB, herbaceous 25 species). Data source and the meaning of symbols as in Fig. 2. 


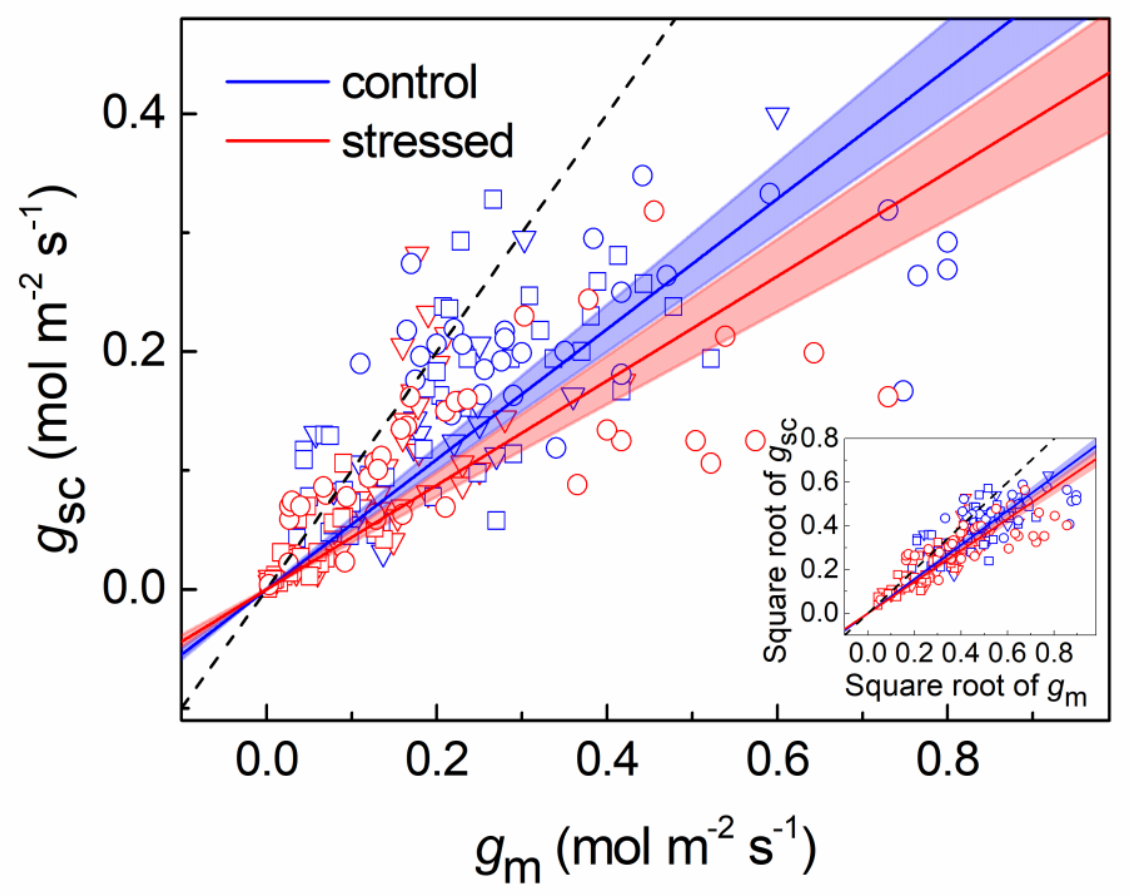

27 Fig. 4 The relation between $g_{\mathrm{m}}$ and $g_{\mathrm{sc}}$ of non-stressed plants (blue solid lines) and drought-stressed

28 plants (red solid line) pooling over plant functional groups. Symbols and species: $\nabla$, deciduous

29 semi-deciduous woody species (DW); $\square$, evergreen woody species (EW); ○, herbaceous species

30 (HB). The internal panel shows the relation between square-root transformed $g_{\mathrm{m}}$ and $g_{\mathrm{sc}}$.

31 Regressions are linear function through the origin across all genotypes with the slope of $0.78 \pm 0.02$

32 (SE) of non-stressed plants $\left(r^{2}=0.20, p<0.0001, n=92\right)$ and $0.72 \pm 0.02$ (SE) of drought-stressed

33 plants $\left(r^{2}=0.58, p<0.0001, n=106\right)$ for the square-root transformed data. The dashed black line is 34 a 1:1 line. 


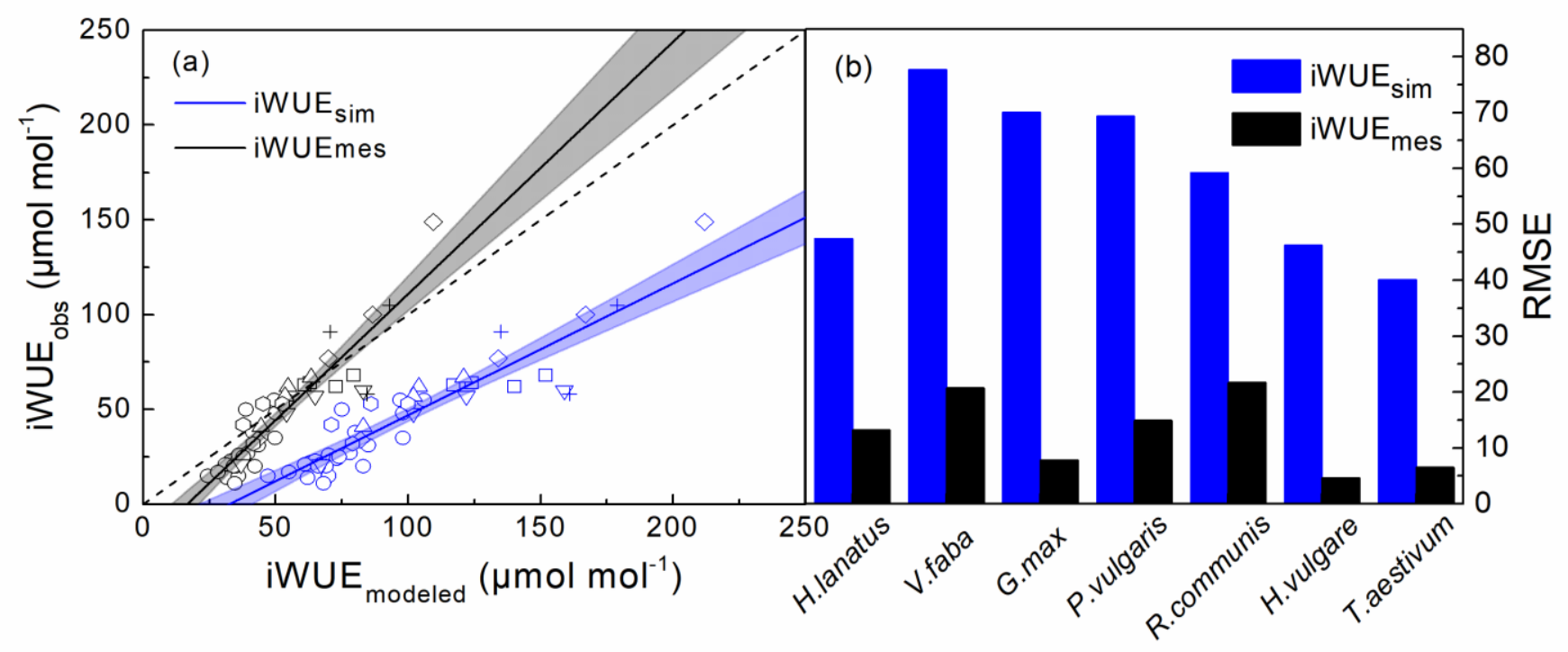

36 Fig. 5 iWUE calculated from photosynthetic $\Delta$ using the simple model (iWUE $\mathrm{im}_{\text {sim }}$ ) and the iWUE

37 model compared to the measured iWUE (iWUE ${ }_{\text {obs }}$ ) a) and the comparison of RMSE of the two

38 models b). Symbols and species: $\square$, G. max; ○, H. lanatus; $\triangle$, H. vulgare; $\nabla, P$. vulgaris; $\diamond, R$.

39 communis; $\bigcirc$, T. aestivum; +, V. faba. The solid lines are least-squares linear regressions: (a)

$40 \quad \mathrm{iWUE}_{\mathrm{obs}}=-22.5( \pm 4.7)+0.7( \pm 0.05) \mathrm{iWUE}_{\mathrm{sim}}, \quad r^{2}=0.84, \quad p<0.0001 ; \quad$ (b) $\mathrm{iWUE}_{\mathrm{obs}}=-22( \pm 4.7)+1.3$

$41( \pm 0.09) \mathrm{iWUE}_{\mathrm{mes}}, r^{2}=0.84, p<0.0001$. Values are mean $\pm \operatorname{SE}(n=46)$. The dashed black line is a 1:1 42 line. 

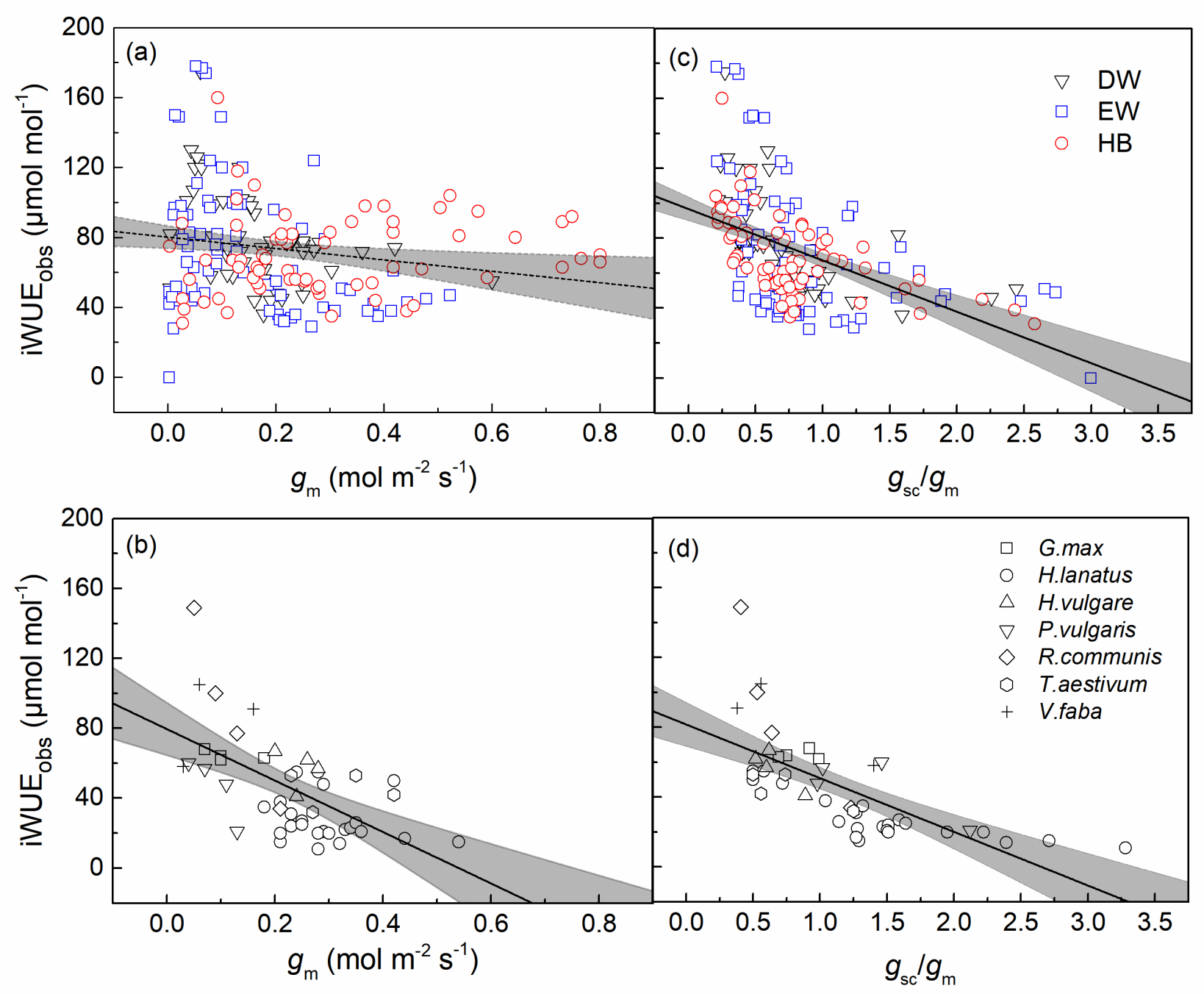

44 Fig. 6 Relation between the measured iWUE (iWUE ${ }_{o b s}$ ) and $g_{m}$ of a) synthesized drought-stress

45 dataset and b) experimental dataset of Table 2; The lines are least-squares linear regressions across

46 all species: a) iWUE=80.10( \pm 3.29$)-32.56( \pm 12.46) g_{\mathrm{m}}, \quad r^{2}=0.03, \quad p<0.01, \quad n=198$;

47 iWUE=79.52( \pm 7.48$)-147.12( \pm 29.03) g_{\mathrm{m}}, \quad r^{2}=0.37, \quad p<0.0001, \quad n=46 ; \quad$ c) iWUE=96.75( \pm 3.43$)-$

$4829.39( \pm 3.63) g_{\mathrm{sc}} / g_{\mathrm{m}}, \quad r^{2}=0.25, \quad p<0.0001, \quad n=198 ; \quad$ d) $\mathrm{iWUE}=81.67( \pm 6.25)-30.77( \pm 4.69) g_{\mathrm{sc}} / g_{\mathrm{m}}$

$49 r^{2}=0.50, p<0.0001, n=46$; values are mean \pm SE. 

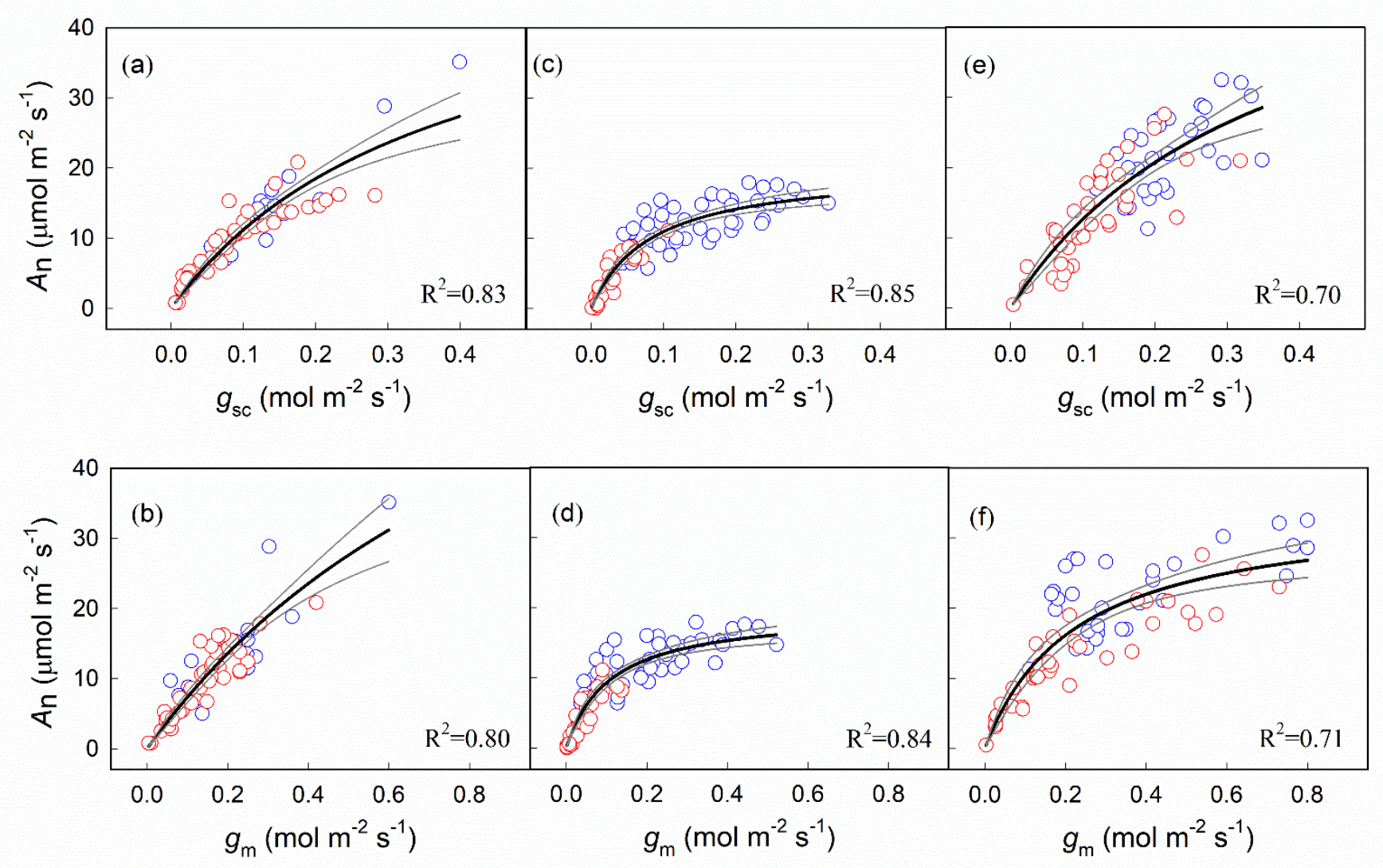

52 Fig. S1 Relationships between $A_{\mathrm{n}}$ and $g_{\mathrm{sc}}$, or $g_{\mathrm{m}}$ across two water availability levels (control,

53 blue dots and drought stress, red dots) for the DW (a and b), EW (c and d), and HB (e and f).

54 Data were fitted use a function of $\mathrm{y}=a \mathrm{x} /(b+\mathrm{x}), n=58$ for DW, $n=74$ for $\mathrm{EW}, n=66$ for $\mathrm{HB}$, and $55 p<0.0001$ for all regressions. 


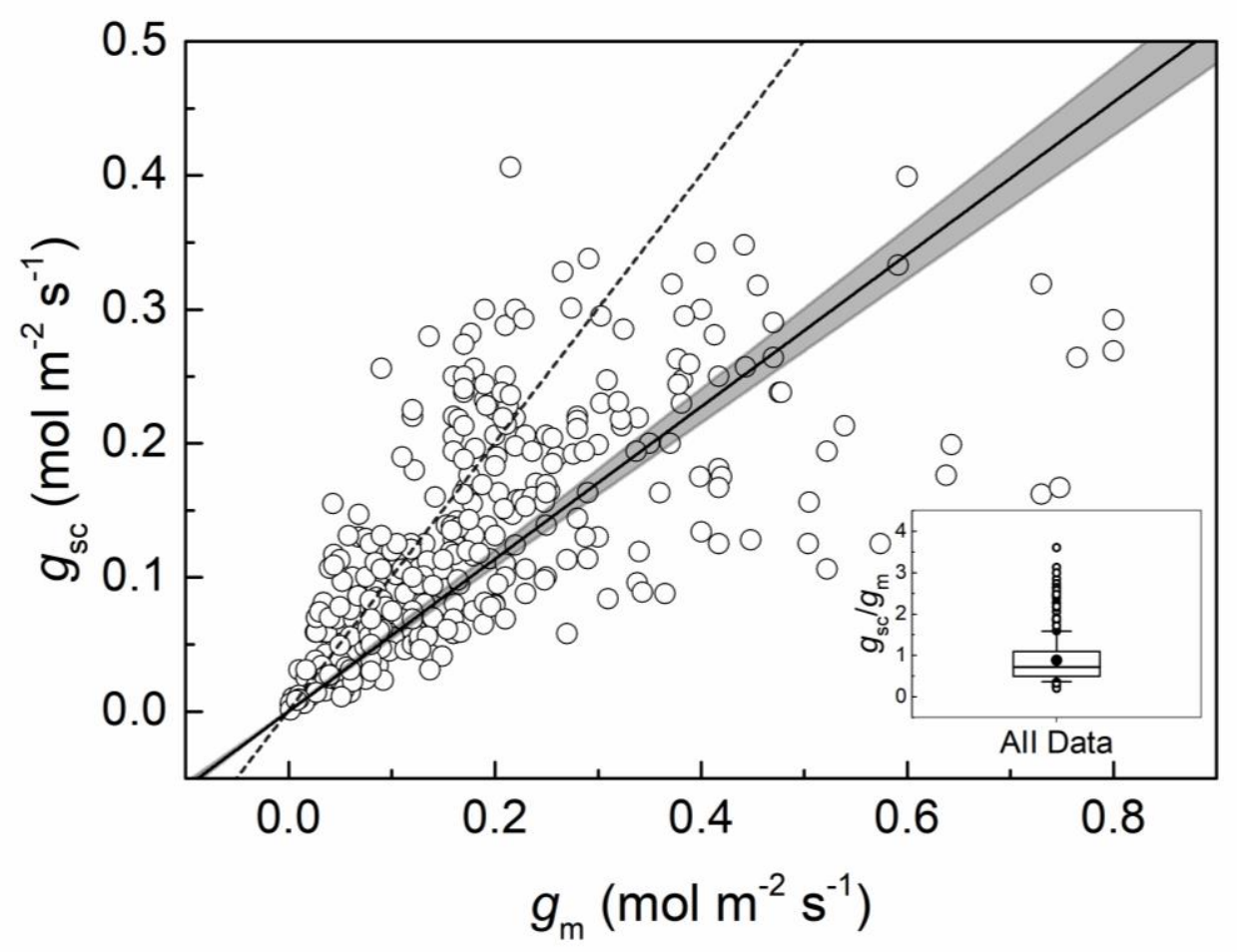

57 Fig. S2 The relation between $g_{\mathrm{m}}$ and $g_{\mathrm{sc}}$ across treatments and species in the main dataset compiled 58 from the published papers. The internal panel shows a box plot of $g_{\mathrm{sc}} / g_{\mathrm{m}}$ calculated from the same 59 data with a mean $g_{\mathrm{sc}} g_{\mathrm{m}}=0.88( \pm 0.0695 \% \mathrm{CI})$. The dashed line is a $1: 1$ line, and the solid line is the 60 regression line: $r^{2}=0.47, p<0.0001, n=364$. 


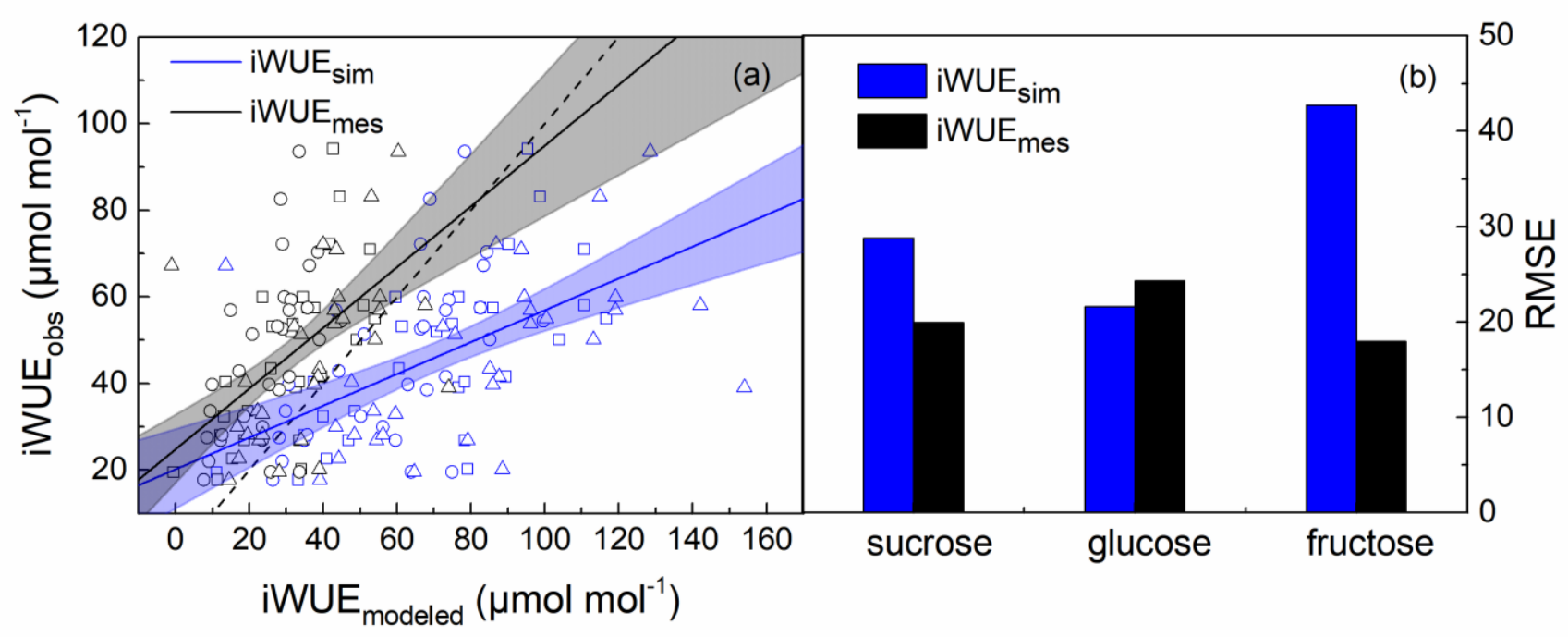

62 Fig. S3 Comparison of the measured iWUE ${ }_{\text {obs }}$ and the modeled iWUE using the simple

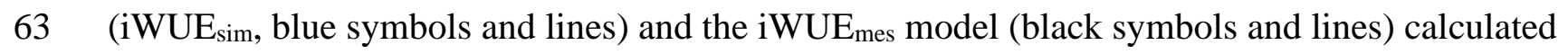

64 from the data of Smith et al. (2016) using Eqn 13. Symbols and leaf metabolites: $\square$, sucrose; 。,

65 glucose; $\triangle$, fructose. The dashed black line is a 1:1 line. The solid lines are least-squares linear

66 regressions: $\mathrm{iWUE}_{\mathrm{obs}}=20.17( \pm 4.63)+0.37( \pm 0.06) \mathrm{iWUE}_{\mathrm{sim}}, r^{2}=0.30, p<0.0001$;

$67 \mathrm{iWUE}_{\mathrm{obs}}=24.57( \pm 3.97)+0.69( \pm 0.11) \mathrm{iWUE}_{\mathrm{mes}}, r^{2}=0.30, p<0.0001$. Values are mean $\pm \operatorname{SE}(n=90)$. 


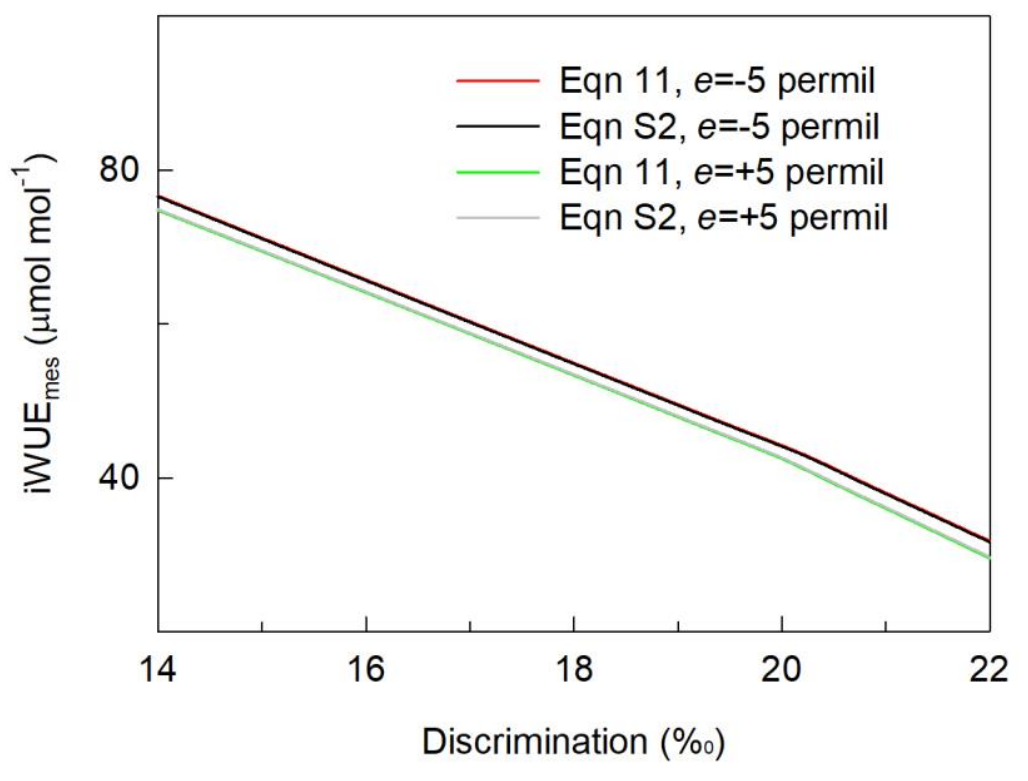

Fig. S4 Comparison of the iWUEmes prediction estimated from Eqn 11 and S2 as affected by the 70 influence of mitochondrial respiratory fractionation $(e)$ 
71 Table S1 Variables used for sensitivity tests. $g_{\text {sc }}$ and $c_{\text {i }}$ were stepwise increased to create a 72 gradient of photosynthetic discrimination, and iWUE models were used to calculate iWUE $\mathrm{sim}_{\text {, }}$ 73 iWUE mes, $_{\text {, and }}$ iWUE $E_{\text {com. }}$.

74

\begin{tabular}{|c|c|c|c|}
\hline $\begin{array}{l}\text { Variable } \\
\text { (units) }\end{array}$ & Definition & $\begin{array}{l}\text { Fixed value } \\
\text { (standard scenario) }\end{array}$ & Manipulations \\
\hline$g_{\mathrm{sc}}\left(\mathrm{mol} \mathrm{m}^{-2} \mathrm{~s}^{-1}\right)$ & $\begin{array}{l}\text { Stomatal conductance to } \\
\mathrm{CO}_{2}\end{array}$ & $\begin{array}{l}\text { step-wise increased from } \\
0.05 \text { to } 0.25\end{array}$ & $\begin{array}{l}\text { step-wise increased from } 0.05 \text { to } \\
0.25\end{array}$ \\
\hline$c_{\mathrm{i}}\left(\mu \mathrm{mol} \mathrm{mol} \mathrm{m}^{-1}\right)$ & $\begin{array}{l}\mathrm{CO}_{2} \text { concentration in the } \\
\text { substomatal cavity }\end{array}$ & $\begin{array}{l}\text { step-wise increased from } \\
250 \text { to } 350\end{array}$ & $\begin{array}{l}\text { step-wise increased from } 250 \text { to } \\
350\end{array}$ \\
\hline$W\left(\mathrm{mmol} \mathrm{mol}^{-1}\right)$ & $\begin{array}{l}\text { leaf-to-air vapor } \\
\text { concentration difference }\end{array}$ & 10 & $5,10,40$ \\
\hline$c_{\mathrm{a}}\left(\mu \mathrm{mol} \mathrm{mol}{ }^{-1}\right)$ & $\begin{array}{l}\mathrm{CO}_{2} \text { concentration in the } \\
\text { atmosphere }\end{array}$ & 400 & \\
\hline$c_{\mathrm{c}}\left(\mu \mathrm{mol} \mathrm{\textrm {mol } ^ { - 1 } )}\right.$ & $\begin{array}{l}\mathrm{CO}_{2} \text { concentration in the } \\
\text { chloroplast }\end{array}$ & $c_{\mathrm{c}}=c_{\mathrm{i}}-A_{\mathrm{n}} / g_{\mathrm{m}}$ & $c_{\mathrm{c}}=c_{\mathrm{i}}-A_{\mathrm{n}} / g_{\mathrm{m}}$ \\
\hline$g_{\mathrm{m}}\left(\mathrm{mol} \mathrm{m} \mathrm{m}^{-2} \mathrm{~s}^{-1}\right)$ & mesophyll conductance & $g_{\mathrm{sc}} / g_{\mathrm{m}}=0.8$ & $g_{\mathrm{sc}} / g_{\mathrm{m}}=0.4,0.8,1.6$ \\
\hline$g_{\mathrm{bc}}\left(\mathrm{mol} \mathrm{m}^{-2} \mathrm{~s}^{-1}\right)$ & $\begin{array}{l}\text { boundary layer conductance } \\
\text { to } \mathrm{CO}_{2}\end{array}$ & 5 & $1,5,+\infty$ \\
\hline$g_{\text {ac }}\left(\mathrm{mol} \mathrm{m}^{-2} \mathrm{~s}^{-1}\right)$ & $\begin{array}{l}\text { conductance to } \mathrm{CO}_{2} \text { of the } \\
\text { stomata plus boundary layer }\end{array}$ & $g_{\mathrm{ac}}=1 /\left(1 / g_{\mathrm{sc}}+1 / g_{\mathrm{bc}}\right)$ & $g_{\mathrm{ac}}=1 /\left(1 / g_{\mathrm{sc}}+1 / g_{\mathrm{bc}}\right)$ \\
\hline$t$ & ternary correction factor & $t=\left(1+a_{\mathrm{ac}}\right) \mathrm{E} / 2 g_{\mathrm{ac}}$ & $t=\left(1+a_{\mathrm{ac}}\right) \mathrm{E} / 2 g_{\mathrm{ac}}$ \\
\hline$a_{\mathrm{ac}}(\%)$ & $\begin{array}{l}\text { combined fractionation for } \\
\mathrm{CO}_{2} \text { diffusion across the } \\
\text { boundary layer and the } \\
\text { stomata }\end{array}$ & $a_{\mathrm{ac}}=a_{\mathrm{b}} g_{\mathrm{ac}} / g_{\mathrm{bc}}+a_{\mathrm{s}} g_{\mathrm{ac}} / g_{\mathrm{sc}}$ & $a_{\mathrm{ac}}=a_{\mathrm{b}} g_{\mathrm{ac}} / g_{\mathrm{bc}}+a_{\mathrm{s}} g_{\mathrm{ac}} / g_{\mathrm{sc}}$ \\
\hline$a_{\mathrm{b}}(\% \mathrm{o})$ & $\begin{array}{l}\text { fractionation during } \mathrm{CO}_{2} \\
\text { diffusion across the } \\
\text { boundary layer }\end{array}$ & 2.9 & - \\
\hline$a_{\mathrm{s}}(\% \mathrm{o})$ & $\begin{array}{l}\text { fractionation during } \mathrm{CO}_{2} \\
\text { diffusion through the } \\
\text { stomata }\end{array}$ & 4.4 & - \\
\hline$a_{\mathrm{m}}(\%)$ & $\begin{array}{l}\text { fractionation associated with } \\
\mathrm{CO}_{2} \text { dissolution and } \\
\text { diffusion in the mesophyll }\end{array}$ & 1.8 & - \\
\hline$b(\%)$ & $\begin{array}{l}\text { fractionation by Rubisco } \\
\text { carboxylation }\end{array}$ & 29 & - \\
\hline$e(\%)$ & $\begin{array}{l}\text { fractionation by } \\
\text { mitochondrial respiration }\end{array}$ & -5 & $0,-5,-10$ \\
\hline$R_{\mathrm{d}}\left(\mu \mathrm{mol} \mathrm{m} \mathrm{m}^{-2} \mathrm{~s}^{-1}\right)$ & day respiration rate & 0.5 & - \\
\hline$A_{\mathrm{n}}\left(\mu \mathrm{mol} \mathrm{m} \mathrm{m}^{-2} \mathrm{~s}^{-1}\right)$ & Net assimilation rate & $\begin{array}{l}A_{\mathrm{n}}=g_{\mathrm{ac}}\left(C_{\mathrm{a}}-C_{\mathrm{i}}\right)- \\
1.6 g_{\mathrm{ac}} W\left(C_{\mathrm{a}^{-}}-C_{\mathrm{i}}\right) / 2\end{array}$ & $A_{\mathrm{n}}=g_{\mathrm{ac}}\left(C_{\mathrm{a}}-C_{\mathrm{i}}\right)-1.6 g_{\mathrm{ac}} W\left(C_{\mathrm{a}}-C_{\mathrm{i}}\right) / 2$ \\
\hline$\Gamma^{*}\left(\mu \mathrm{mol} \mathrm{mol}^{-1}\right)$ & $\begin{array}{l}\mathrm{CO}_{2} \text { compensation point in } \\
\text { the absence of } \\
\text { mitochondrial respiration }\end{array}$ & 35 & - \\
\hline$f(\%)$ & $\begin{array}{l}\text { fractionation during } \\
\text { photorespiration }\end{array}$ & $11 \%$ & $0,11,20$ \\
\hline$E$ & transpiration rate & $E=1.6 g_{\mathrm{ac}} W$ & $E=1.6 g_{\mathrm{ac}} W$ \\
\hline
\end{tabular}


76 Note S1 Derivation of Eqn 8 from the comprehensive photosynthetic discrimination model.

77 Using the notations $e^{\prime}=e \alpha_{b} / \alpha_{e}, f^{\prime}=f \alpha_{b} / \alpha_{f}$, and substituting $c_{\mathrm{c}}$ by $c_{\mathrm{i}}-A_{\mathfrak{n}} / g_{\mathrm{m}}$, Eqn 3 gives:

78

$$
\begin{aligned}
(1-t) c_{a} \Delta= & a_{a c} c_{a}+(1+t)\left[\frac{A_{n}}{g_{m}}\left(a_{m}-b+e^{\prime} \frac{R_{d}}{A_{n}+R_{d}}\right)-f^{\prime} \Gamma^{*}+e^{\prime} \frac{R_{d} \Gamma^{*}}{A_{n}+R_{d}}\right] \\
& +c_{i}\left[-a_{a c}+(1+t)\left(b-e^{\prime} \frac{R_{d}}{A_{n}+R_{d}}\right)\right]
\end{aligned}
$$

80

81 Rewriting $A_{n} / g_{m}$ as $\left(A_{n} / k g_{a c}\right) k g_{a d} / g_{m}=\mathrm{iWUE}^{*}{ }_{\mathrm{com}} k g_{a d} / g_{m}$ and using Eqn 7 leads to:

$$
\begin{aligned}
& (1-t) c_{a} \Delta=a_{a c} c_{a}+(1+t)\left[i W U E_{c o m}^{*} \frac{k g_{a c}}{g_{m}}\left(a_{m}-b+e^{\prime} \frac{R_{d}}{A_{n}+R_{d}}\right)-f^{\prime} \Gamma^{*}+e^{\prime} \frac{R_{d} \Gamma^{*}}{A_{n}+R_{d}}\right] \\
& +\frac{c_{a}\left(\frac{1}{k}-\frac{W}{2}\right)-\mathrm{iWUE}_{\mathrm{com}}^{*}}{\frac{1}{k}+\frac{W}{2}}\left[-a_{a c}+(1+t)\left(b-e^{\prime} \frac{R_{d}}{A_{n}+R_{d}}\right)\right]
\end{aligned}
$$

84

85 Rearranging (factorization by iWUE* ${ }^{*}$ ) gives:

86

$$
\begin{aligned}
& (1-t) c_{a} \Delta=a_{a c} c_{a}(1-\varepsilon)+(1+t)\left[c_{a} \varepsilon\left(b-e^{\prime} \frac{R_{d}}{A_{n}+R_{d}}\right)+\Gamma^{*}\left(e^{\prime} \frac{R_{d} \Gamma^{*}}{A_{n}+R_{d}}-f^{\prime}\right)\right] \\
& \quad+\operatorname{iWUE}_{\mathrm{com}}^{*}\left[k(1+t) \frac{g_{a c}}{g_{m}}\left(a_{m}-b+e^{\prime} \frac{R_{d}}{A_{n}+R_{d}}\right)-\frac{(1+t)\left(b-e^{\prime} \frac{R_{d}}{A_{n}+R_{d}}\right)-a_{a c}}{\frac{1}{k}+\frac{W}{2}}\right]
\end{aligned}
$$

88

89 where $\varepsilon$ is defined by Eqn 9. Rearranging to express iWUE ${ }^{*}$ com gives Eqn 8). 
Note S2 The modified carbon isotope discrimination model for partitioning day respiration and its isotopic contribution to photosynthetic discrimination

92 The comprehensive model of Eqn 3 can be modified as:

$93 \Delta=\frac{1}{1-t}\left[a_{a c} \frac{c_{a}-c_{i}}{c_{a}}\right]+\frac{1+t}{1-t}\left[a_{m} \frac{c_{i}-c_{c}}{c_{a}}+b \frac{c_{c}}{c_{a}}+\frac{\alpha_{b}}{\alpha_{e}} e \frac{R_{d}^{\prime}}{A_{n}}-\frac{\alpha_{b}}{\alpha_{f}} f \frac{\Gamma^{*}}{c_{a}}\right]$

94 by assuming that day respiration is separated from the pool of primary assimilates during a short exposure to an atmosphere with a different $\delta^{13} \mathrm{C}$ value in $\mathrm{CO}_{2}$. Furthermore, $R_{\mathrm{d}}$ ' is defined as the respired $\mathrm{CO}_{2}$ that is released into the ambient air, thus is a net flux whereas $R_{\mathrm{d}}$ in the original Farquhar model was defined as a gross respiratory flux (net and gross referring here to refixation) (Tcherkez et al. 2017). That is, $R_{d}$ ' is considered as the flux of $\mathrm{CO}_{2}$ liberated by the leaf from respiratory substrates with a slow turn-over and thus not influenced by the isotope composition of photosynthetic assimilates in the short term. Using Eqn S1, $R_{\mathrm{d}}$ ' can be estimated from measurements of online isotope discrimination in a gas exchange system where inlet $\mathrm{CO}_{2}$ can be switched between two sources of $\mathrm{CO}_{2}$ with contrasted $\delta^{13} \mathrm{C}$ values. More details are provided in Gong et al. (2015; 2018).

We can then derive equations for iWUE similarly as in Note $\mathrm{S} 1$. Using the notations $e^{\prime}=$ $e \alpha_{b} / \alpha_{e}, f^{\prime}=f \alpha_{b} / \alpha_{f}$, and substituting $c_{\mathrm{c}}$ by $c_{\mathrm{i}}-A_{\mathrm{n}} / g_{\mathrm{m}}$, Eqn $\mathrm{S} 1$ gives:

$$
(1-t) c_{a} \Delta=a_{a c} c_{a}+(1+t)\left[\frac{A_{n}}{g_{m}}\left(\left(a_{m}-b\right)-e^{\prime} \frac{R_{d}{ }^{\prime} c_{a}}{A_{n}}-f^{\prime} \Gamma^{*}\right)\right]+c_{i}\left[-a_{a c}+(1+t) b\right]
$$

107

Rewriting $A_{n} / g_{m}$ as $\left(A_{n} / k_{a c}\right) \times k g_{a d} / g_{m}=\mathrm{iWUE}_{\mathrm{com}}^{\prime} \mathrm{kg}_{a d} / g_{m}$ and using Eqn 7 leads to (the symbol prime for iWUE refers to the fact we now use a "disconnected" respiration term):

$$
\begin{aligned}
& (1-t) c_{a} \Delta=a_{a c} c_{a}+(1+t)\left[\mathrm{iWUE}_{\mathrm{com}}^{\prime} \frac{k g_{a c}}{g_{m}}\left(a_{m}-b\right)-e^{\prime} \frac{R_{d}{ }^{\prime} c_{a}}{A_{n}}-f^{\prime} \Gamma^{*}\right] \\
& +\frac{c_{a}\left(\frac{1}{k}-\frac{W}{2}\right)-\mathrm{iWUE}_{\mathrm{com}}^{\prime}}{\frac{1}{k}+\frac{W}{2}}\left[-a_{a c}+(1+t) b\right]
\end{aligned}
$$

113 Rearranging (factorization by iWUE' com) gives:

$$
\mathrm{iWUE}_{\mathrm{com}}^{\prime}=c_{a} \frac{a_{a c}(1-\varepsilon)+(1+t)\left(\varepsilon b-\frac{e^{\prime} R_{d^{\prime}}}{A_{n}}-f^{\prime} \frac{\Gamma^{*}}{c_{a}}\right)-(1-t) \Delta}{\frac{(1+t) b-a_{a c}}{\frac{1}{k}+\frac{W}{2}}-(1+t) k \frac{g_{a c}}{g_{m}}\left(a_{m}-b\right)}
$$


115 Again, ignoring ternary corrections and boundary layer resistance $\left(t=0, \varepsilon=1, c_{\mathrm{a}}=c_{\mathrm{s}}, g_{\mathrm{as}}=g_{\mathrm{sc}}, a_{\mathrm{ac}}=\right.$

$\left.116 a_{\mathrm{s}}\right)$, Eqn S2 simplifies to:

$117 \quad \mathrm{iWUE}_{\text {mes }}^{\prime}=\frac{c_{a}}{k} \frac{b-\Delta-f^{\prime} \frac{\Gamma^{*}}{c_{a}}-e^{\frac{R_{d}^{\prime}}{A_{n}}}}{b-a_{s}+\frac{g_{S c}}{g_{m}}\left(b-a_{m}\right)}$

118 If we further neglect the term associated with day respiration, Eqn S3 simplifies to Eqn 12. Using 119 a series of theoretical data of the standard scenario (Table S1, $g_{\mathrm{sc}} / g_{\mathrm{m}}=0.8$ ), we calculated iWUE' mes 120 (Eqn S3) and compared with iWUE $_{\text {mes }}$ (Eqn 11), showing that the estimates provided by the two 121 equations (which account for the respiratory fractionation term differently) were very similar (the 122 difference being less than $1 \mu \mathrm{mol} \mathrm{mol}^{-1}$, see below). Taken as a whole, within a range of intrinsic 123 respiratory fractionation $e$ (far from very high, artificial isotopic disequilibrium), day respiration

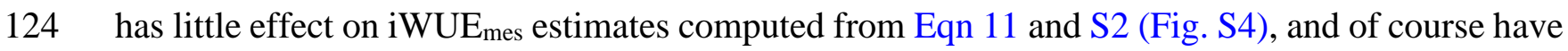
125 no effect at all on $\mathrm{iWUE}_{\mathrm{mes}}$ estimates generated by Eqn 12 which neglects the respiratory isotope 126 contribution. 